\title{
EL DERECHO AL OLVIDO EN INTERNET: DEBATES CERRADOS \\ Y CUESTIONES ABIERTAS TRAS LA STJUE GOOGLE VS AEPD Y MARIO COSTEJA
}

JUAN MARÍA MARTÍNEZ OTERO 
SUMARIO

1. INTRODUCCIÓN: EL DERECHO AL OLVIDO... ¿MISIÓN IMPOSIBLE? 2. CUESTIONES PREVIAS: AGENTES IMPLICADOS E INTERESES EN LIZA. 3. EL DERECHO AL OLVIDO RESPECTO DE CONTENIDOS ILEGALES. 4. EL DERECHO AL OLVIDO RESPECTO DE CONTENIDOS LEGALES. 5. ESTADO DE LA CUESTIÓN: MÁS DUDAS QUE CERTEZAS. 6. CONCLUSIONES (INCONCLUSAS). 7. BIBLIOGRAFÍA 


\title{
EL DERECHO AL OLVIDO EN INTERNET: DEBATES CERRADOS Y CUESTIONES ABIERTAS TRAS LA STJUE GOOGLE VS AEPD Y MARIO COSTEJA
}

\author{
JUAN MARÍA MARTÍNEZ OTERO \\ Profesor de Derecho de la Comunicación \\ Universidad CEU-Cardenal Herrera
}

\section{INTRODUCCIÓN: EL DERECHO AL OLVIDO... ¿MISIÓN IMPOSIBLE?}

Se ha escrito que Dios perdona y olvida; los hombres perdonan, pero no olvidan; y la naturaleza ni perdona ni olvida. Pues bien, algo parecido a lo predicado de la naturaleza podría decirse de Internet: que ni perdona ni olvida ${ }^{1}$. La tecnología digital permite que en la Red de redes la información perviva indefinidamente, desafiando a nuestro refranero en aquello de que no bay mal que cien años dure. Ciertamente, el carácter imperecedero de las informaciones contenidas en Internet preocupa, en particular a quienes han visto su reputación o su honra comprometida por una determinada información publicada en la Red. Si antaño toda información se deslizaba ineluctablemente hacia el pozo del olvido —el

${ }^{1}$ La comparación entre la memoria digital y la divina es empleada en el contexto del derecho al olvido por la comisaria europea de justica en: Reding, V. (2010). «Why the EU needs new personal data protection rules?», The European Data protection and Privacy Conference, Bruselas. Disponible en: http://europa.eu/rapid/press-release_SPEECH-10-700_en.htm (última visita: 01.02.2015). 
papel del periódico de hoy envuelve el pescado de mañana, decían los viejos maestros del periodismo en un impostado acto de humildad gremial-, hogaño las tecnologías digitales permiten traer al presente casi cualquier información, con sorprendente rapidez y sin ningún coste, produciendo lo que se ha dado en llamar el efecto eterno de la información, fruto de la memoria total de Internet ${ }^{2}$. A menudo se afirma con orgullo y entusiasmo que Internet ha roto las fronteras de espacio y tiempo. Y es verdad. Ahora bien, esa ruptura no siempre es ventajosa para los individuos. Al menos para aquellos a los que les gustaría que el tiempo pasara y restañase una herida, o empujara lentamente hacia el olvido un insulto, una calumnia, un error o una mancha.

Es en este humus donde brota el debate en torno al derecho al olvido. El alumbramiento de este derecho en los albores del siglo xxi trae a la memoria el nacimiento del derecho a la intimidad, a finales del xIX y principios del xx. Aquel derecho, que en sus primeras formulaciones fue descrito como el derecho a ser dejado en paz — to be let alone-, respondía a los avances tecnológicos y a los hábitos de comunicación de aquella época, que permitían la captación de la vida íntima de las personas y su reproducción masiva (cámaras de fotos y de vídeo, micrófonos, extensión de la prensa escrita). El nuevo derecho al olvido - to let it be forgotten, podríamos decir - trata de responder a los avances tecnológicos y comunicativos de hoy, que a través de Internet permiten exponer de manera pública e inmediata gran parte del pasado de una persona ante los ojos de cualquier interesado.

Las diferentes instancias de protección de derechos comienzan a enfrentarse a solicitudes de personas que exigen que sus datos sean retirados de páginas web, de directorios, de hemerotecas o de listas de resultados de buscadores de Internet. Y las respuestas no son sencillas. En nuestro ámbito geográfico, tribunales e instancias administrativas de protección de datos tienen dificultades para aplicar una normativa relativamente joven y ya desfasada a problemáticas de nueva planta, surgidas en el marco de herramientas que evolucionan con gran rapidez ${ }^{3}$. Los paradigmas tecnológicos, comunicativos y sociales han sufrido un giro copernicano en los últimos treinta años, lo que exige de los operadores jurídicos un esfuerzo constante por adaptar sus categorías y respuestas a los nuevos tiempos, a fin de dar soluciones justas a problemas novedosos y, en ocasiones, acuciantes.

2 De Terwangne, C. (2012). «Privacidad en Internet y derecho a ser olvidado / derecho al olvido», Revista de Internet, Derecho y Política, núm. 13, p. 54.

3 Como constata acertadamente Hernández Ramos, «debido a la constante evolución y desarrollo de la tecnología (...) la legislación que intenta embridar jurídicamente este campo se queda anticuada con rapidez». Hernández Ramos, M. (2013). «El derecho al olvido digital en la web 2.0», Cuadernos de la Cátedra de Seguridad Salmantina, núm. 11, p. 20. 
En el debate sobre el derecho al olvido se discuten, entre otras, las siguientes preguntas: ¿Cómo se debe configurar el derecho a la protección de datos en Internet? ¿Es posible conjugar los derechos comunicativos con la intimidad de las personas? ¿Qué responsabilidad cabe imputar a los diferentes prestadores de servicios en la Red? ¿Deben los buscadores de Internet responder de los contenidos que analizan, indexan y ofrecen? ¿Puede borrarse el pasado de una persona de Internet? ¿Debe hacerse? ¿A qué precio? ¿Al de restringir la libertad de expresión en Internet, o el derecho a la información de sus usuarios? ¿No se abriría de este modo la puerta a un control de contenidos en la Red, rayano en la censura? ¿Qué capacidad de decisión debemos reconocer a los buscadores de Internet sobre los contenidos que indexan? ¿Deberían actuar ciegamente o, por el contrario, incorporar criterios de oportunidad en su indexación, retirando de sus listas de resultados aquellos especialmente ofensivos? ¿Quién está legitimado para solicitarles dicha retirada? Todos estos interrogantes, que pueden multiplicarse indefinidamente, se resumen en los siguientes cuatro: ¿Existe el derecho al olvido? ¿Quién puede exigirlo? ¿Respecto de qué contenidos? Y, finalmente, ¿frente a quién?

A lo largo de las siguientes páginas se intenta enfocar adecuadamente estas cuestiones, resumir las principales respuestas ensayadas por la jurisprudencia y la doctrina hasta la fecha, y ofrecer algunas reflexiones jurídicas que puedan contribuir a la búsqueda de soluciones proporcionadas y justas a estas preguntas, tan apasionantes como difíciles de resolver.

\section{CUESTIONES PREVIAS: AGENTES IMPLICADOS E INTERESES EN LIZA}

A fin de hacer una aproximación lo más sistemática posible al llamado derecho al olvido y sus implicaciones legales, resulta oportuno esclarecer de inicio quiénes son los agentes implicados en estos conflictos, y cuáles son los intereses y derechos subjetivos en conflicto.

En la mayoría de los casos el derecho al olvido se plantea en relación con un determinado contenido referido a una persona física, que ha sido publicado en Internet por un editor, y al que normalmente se accede a través de un enlace ofrecido por un buscador para la búsqueda asociada al nombre de la persona física afectada. Así pues, los sujetos implicados en el posible conflicto son cuatro:

Editor. Se trata de la persona que ha publicado en Internet la información que incomoda, la opinión que hiere, y que el afectado desearía ver suprimida. 
Motor de búsqueda o buscador. Como es sabido, los motores de búsqueda rastrean la web para indexar el contenido y ofrecerlo de modo ordenado a sus usuarios, dentro de una lista de resultados para cada búsqueda concreta. Sin su tarea de indexación, búsqueda y ordenación de resultados, la World Wide Web no sería más que una inmensa biblioteca desordenada, empleando la afortunada expresión de Umberto Eco.

Internauta. El internauta es la persona que navega por Internet y que accede a la información contenida en la misma, bien directamente, bien a través de un buscador.

Protagonista del mensaje, afectado o interesado. El protagonista o afectado es el sujeto sobre el que recae el mensaje publicado, quien pretende que sus datos o determinada información que le afecta deje de estar disponible en Internet - ya sea eliminando el contenido, ya sea suprimiendo los enlaces al mismo en los resultados de los buscadores.

Una vez identificados los sujetos implicados, es conveniente detenerse brevemente en los derechos afectados, la mayoría de los cuales ha sido objeto de una reiterada interpretación jurisprudencial tanto en el ámbito doméstico como internacional. Quien publica la información y el internauta ejercerán sus derechos comunicativos (art. 20.1 a y d CE), el primero en su dimensión activa —emisión-, y el segundo en su dimensión pasiva — recepción. El buscador, prima facie, ejerce su derecho constitucional a la libertad de empresa (art. $38 \mathrm{CE}$ ), aunque cabría preguntarse si su tarea no supone igualmente un ejercicio de los derechos comunicativos, habida cuenta de su protagonismo en la efectiva difusión y acceso a un determinado mensaje. Por su parte, el afectado podrá ver vulnerados sus derechos fundamentales a la protección de datos personales (art. $18.4^{\circ} \mathrm{CE}$ ), al honor, intimidad y propia imagen (art. $18 \mathrm{CE}$ ), a la integridad física o psíquica (art. $15 \mathrm{CE}$ ), y a la dignidad humana y al libre desarrollo de la personalidad ${ }^{4}$.

Los potenciales conflictos de derechos que pueden suscitarse normalmente enfrentarán el derecho a la libertad de empresa del buscador y los derechos comunicativos del editor y el internauta, con el derecho a la protección de datos per-

${ }^{4}$ En nuestro entorno, ha sido Simón Castellano quién ha subrayado la intrínseca conexión entre el derecho al olvido y el derecho a la dignidad humana y al libre desarrollo de la personalidad. Simón Castellano, P. (2012). El régimen constitucional del derecho al olvido digital, Valencia, Tirant lo Blanch, p. 116 y ss. También cabe pensar en contenidos que afectan a la propiedad intelectual del interesado, como puede ser un enlace a una página de descarga gratuita de una de sus obras. En estos casos, sin embargo, no estamos ante una cuestión vinculada con el derecho al olvido, sino con los derechos de autor. El análisis de este tipo de conflictos excede el objeto del presente trabajo. 
sonales de la persona afectada por el mensaje. Además, cuando el contenido del mensaje sea ilegal, también podrán verse afectados los derechos al honor, la intimidad y la propia imagen del afectado.

Como ha reiterado la jurisprudencia a todos los niveles, no existen derechos absolutos, por lo que cuando se produzca una colisión de derechos subjetivos, será necesario hacer una ponderación de los derechos en liza para determinar cuál de ellos debe prevalecer ${ }^{5}$. En el supuesto del derecho al olvido, será preciso pues determinar si deben primar los derechos comunicativos y de libertad de empresa, o los derechos a la protección de datos y al honor, la intimidad y la propia imagen ${ }^{6}$. Teniendo en cuenta que todos estos derechos están recogidos en la Constitución, y la mayoría de ellos tienen carácter de derechos fundamentales, la cuestión no es baladí, y sea cual sea el resultado de la ponderación, quedarán comprometidos derechos de gran trascendencia tanto para el individuo como para la comunidad.

Veamos brevemente cuál es la configuración constitucional, legal y jurisprudencial de los derechos en conflicto, para poder confrontarlos con rigor y coherencia.

En cuanto a los derechos a la libertad de expresión y a la información, en relación con el honor, la intimidad y la propia imagen, resultan necesarias unas aclaraciones previas ${ }^{7}$. El principal límite de la libertad de expresión es el insulto, de modo que aquellos contenidos de carácter injurioso o calumnioso contenidos en Internet podrán ser reputados como ilícitos ${ }^{8}$. Por su parte, el límite del derecho a la información es la veracidad. Cualquier mensaje objetivo, para estar constitucionalmente protegido, deberá ser veraz, lo que significa que deberá haber sido mínimamente contrastado: la persona que lo emite debe tener un cierto grado de

5 El carácter limitado de los derechos fundamentales fue reconocido muy tempranamente por la jurisprudencia constitucional. Así, la STC 11/1981, de 8 de abril, señala en su F. J. $7^{\circ}$ : «ningún derecho, ni aún los de naturaleza o carácter constitucional, pueden considerarse como ilimitados».

6 Para analizar las principales construcciones jurisprudenciales sobre la ponderación de los derechos comunicativos en caso de colisión con otros derechos, véanse las SSTC 105/1990, de 6 de junio, relativa al caso José María García; 171 y 172/1990, de 12 de noviembre, relativas a un accidente de aviación y a su tratamiento por parte de los diarios El País y Diario 16; y 197/1991, de 17 de octubre, relativa al caso Sara Montiel.

7 Los derechos al honor, la intimidad y la propia imagen han sido desarrollados fundamentalmente mediante la Ley Orgánica 1/1982, de 5 de mayo, de Protección Civil del Derecho al Honor, a la Intimidad Personal y Familiar y a la Propia Imagen.

${ }^{8}$ Entre la ingente jurisprudencia sobre el particular, cabe citar la STC 105/1990, de 6 de junio, F. J. 4º y la STEDH Gorelishvili c. Georgia, de 5 de septiembre de 2007, párrafo 40. 
seguridad de que lo que afirma es efectivamente cierto 9 . Aquellos mensajes informativos no contrastados, emitidos sin el mínimo de diligencia exigible, no gozarán pues de protección constitucional. Hechas estas aclaraciones, cabe afirmar que cuando entran en colisión los derechos comunicativos con el honor, la intimidad o la propia imagen, primarán los derechos comunicativos cuando se cumplan dos requisitos. En primer lugar, cuando su ejercicio no rebase los límites previamente señalados, a saber: el insulto en la libertad de expresión, y la falta de veracidad en el derecho a la información. Y, en segundo lugar, cuando los mensajes revistan interés público, por la materia o por las personas a las que se refieran ${ }^{10}$.

Por su parte, el derecho fundamental a la protección de datos reconoce a su titular la llamada autonomía o autodeterminación informativa, consistente en la capacidad de la persona de decidir en cada momento qué información personal será revelada, a quién y con qué objetivo ${ }^{11}$. Los principios rectores para el tratamiento de datos consagrados en la LOPD son la veracidad, la temporalidad, la pertinencia y el consentimiento ${ }^{12}$. De todos ellos, reviste una particular importancia este último, consistente en la obligación de quien hace un tratamiento de datos de contar con el consentimiento del afectado, salvo en casos muy tasados previstos en el propio texto legal ${ }^{13}$. En cuanto a los derechos del afectado, la LOPD le reconoce el derecho a la información sobre la existencia y las características del fichero, el derecho de acceso a los datos, y los derechos de oposición y cancelación ${ }^{14}$. Son estos derechos de oposición y cancelación los que se esgrimen cuando se exige el derecho al olvido.

Finalmente, el derecho a la libertad de empresa — que ejercería en este tipo de conflictos el buscador - viene recogido en el artículo 38 de la Constitución. Al tratarse de un derecho reconocido en la parte programática del texto constitucional, el derecho a la libertad de empresa cede en caso de conflicto con un derecho fundamental. Así, cuando se trate de ponderar el derecho a la libertad de empresa de Google u otro buscador con el derecho a la protección de datos de un sujeto particular, la balanza se decantará normalmente hacia la protección del

9 Las principales sentencias que se han ocupado de concretar el alcance de la expresión información veraz son: SSTC 172/1990, de 12 de noviembre; 178/1993, de 31 de mayo; 138/1996, de 16 de septiembre.

10 El concepto de interés público ha sido tratado, entre otras, en las SSTC 178/1993, de 31 de mayo, F. J. 2; 121/2000, de 10 de mayo, F. J. 4; y 52/2002, de 25 de febrero, F. J. $8^{\circ}$

11 De Terwangne, C. (2012). «Privacidad en Internet...», op. cit., p. 55.

12 Arts. 4 y ss LOPD.

13 Art. 6.2 $2^{\circ}$ LOPD.

14 Estos derechos son conocidos como los derechos ARCO. Están reconocidos en los artículos 5. $1^{\circ}$.e y 17 LOPD. 
derecho del particular. Lo que complica la ponderación en estos casos es que, como ya hemos apuntado y se analizará más adelante, no está claro que un buscador no ejerza también el derecho a la información... o que no contribuya de forma casi imprescindible a su efectiva realización.

Hechas estas aclaraciones, podemos abordar ya las cuestiones previamente apuntadas. Nuestro análisis se bifurca en virtud de una necesaria diferenciación, dependiendo del tipo de contenido que el afectado pretenda empujar hacia el olvido, eliminándolo de la Red.

\section{EL DERECHO AL OLVIDO RESPECTO DE CONTENIDOS ILEGALES}

Un primer grupo de contenidos que el afectado puede tratar de eliminar de la Red es el de los contenidos ilegales, entendiendo por tales aquellos que pueden vulnerar algún derecho del afectado más allá del derecho a la protección de datos. Se trataría de mensajes contrarios a los derechos al honor, la intimidad, la propia imagen o la integridad física del afectado, tales como injurias, calumnias, revelación de secretos, fotografías no autorizadas, insultos o amenazas.

Para hacer desaparecer estos contenidos, el interesado tiene una primera vía, ajena todavía al ámbito del Derecho: dirigir una solicitud de retirada al editor del contenido y al buscador que ha indexado el mismo, y esperar la remoción. Si el responsable se pliega a la solicitud, el asunto queda zanjado. Junto con esa solicitud, el afectado puede iniciar un procedimiento judicial que declare la ilegalidad del contenido y ordene su efectiva eliminación de la Red. Esta segunda vía, empero, no está exenta de escollos. Es posible que el responsable del contenido no resida en España o la Unión Europea, lo que puede generar dificultades en cuanto a la jurisdicción competente y el Derecho aplicable. Por otro lado, también cabe la posibilidad de que el responsable del contenido actúe en la Red bajo un nick o avatar, amparado en el anonimato, lo que dificultará la sustanciación de responsabilidades. Finalmente, y por no extendernos, puede suceder que un contenido haya sido copiado y reproducido por diferentes páginas y perfiles de Internet, lo que hará su retirada una misión cuanto menos difícil.

Sea de ello lo que fuere, parece innegable que la responsabilidad original por dichos contenidos, con la consiguiente obligación de retirarlos, corresponde a quien difunde los mismos, normalmente el editor de la página web que los alberga. En efecto, el artículo 13 de la LSSI $^{15}$ reconoce la responsabilidad civil,

15 Ley 34/2002, de 11 de julio, de servicios de la sociedad de la información y de comercio electrónico. 
penal y administrativa de los prestadores de servicios en Internet, categoría en la que se encuadran los editores de páginas web. Por consiguiente, quien quiera ver retirado u olvidado un determinado contenido de Internet por considerarlo ilegal, podrá denunciar al editor a través de las vías jurisdiccionales pertinentes, a fin de que se declare la efectiva ilegalidad del material objeto de litigio y se requiera su retirada de la correspondiente página web.

Admitida esta responsabilidad original del editor, se ha planteado la posibilidad de exigir una responsabilidad derivada a aquellos prestadores de servicios en Internet que contribuyen a la efectiva difusión de dicho contenido ilegal, aunque no lo hayan elaborado ellos. De este modo, la responsabilidad por contenidos ilegales se extendería a los portales colaborativos que alojan los contenidos ilegales — tales como las redes sociales o las páginas de comentarios de noticias de los diarios online-; a las plataformas o servidores que los albergan; $\mathrm{o}$, incluso, a los buscadores que los indexan y difunden ${ }^{16}$. Hecha extensiva esta responsabilidad, los citados prestadores de servicios quedarían obligados a retirar los contenidos ilegales, a fin de restablecer al perjudicado en el pleno disfrute de sus derechos, haciendo efectivo el derecho al olvido digital.

¿Admite la legislación esta responsabilidad derivada? ¿Son los prestadores de servicios de Internet responsables de los contenidos ajenos que albergan, alojan o indexan? La respuesta la encontramos en los artículos 14 y siguientes de la LSSI, que establecen con carácter general el principio de no responsabilidad por contenidos ajenos ${ }^{17}$. No obstante, dicha regla general admite una excepción: los prestadores responderán de los contenidos ajenos cuando, teniendo un cono-

16 Sobre esta cuestión, resulta ilustradora la STS, Sala $1^{\text {a }}$, de 4 de marzo de 2013. Dicha sentencia desestimó una demanda contra Google Inc por enlazar a informaciones presuntamente lesivas del derecho al honor del demandante, al implicarle en la trama de corrupción conocida como Operación Malaya. El TS concluyó que las evidencias enviadas por el recurrente a Google Inc no eran suficientemente elocuentes para que el buscador tuviera un conocimiento efectivo de la ilegalidad de los contenidos enlazados.

17 Resumidamente, cabe concluir con Pérez Velasco y Conde Castejón, que «los proveedores de servicios son responsables por los contenidos que elaboren o que se hayan elaborado por cuenta suya. Por el contrario, no serán responsables por el ejercicio de actividades de intermediación (...). Puede afirmarse que la atribución de responsabilidad jurídica guarda relación con el grado de control sobre la información de los distintos agentes que intervienen en el proceso comunicativo». Pérez Velasco, M. M. y Conde Castejón, J. (2002). «Regulación versus autorregulación en Internet y los nuevos servicios de comunicación», en Régimen jurídico de Internet, Madrid, La Ley, p. 123. En este sentido, resulta ilustrativo Grimalt Servera, P. (2013): «La falta de conocimiento efectivo del prestador del servicio de intermediación de almacenamiento o alojamiento de datos como causa de exoneración de responsabilidad civil. El conflicto entre el derecho al honor y la libertad de expresión», Cuadernos Civitas de Jurisprudencia Civil, núm. 93, pp. 315-341. 
cimiento efectivo de su ilegalidad, no procedan a retirarlos o a hacerlos inaccesibles con la debida diligencia ${ }^{18}$.

En relación con el derecho al olvido, cabe deducir pues que los prestadores de servicios — particularmente los buscadores — estarán obligados a retirar de su página, servidor o lista de resultados un contenido cuando tengan un conocimiento efectivo de su ilegalidad. Este conocimiento efectivo se alcanzará bien cuando el afectado haya comunicado al prestador una sentencia judicial o resolución administrativa que declare la ilegalidad; o bien cuando la misma resulte palmaria tras un somero análisis del contenido ${ }^{19}$. Esta posibilidad de acudir al buscador para que retire de su lista de resultados determinados contenidos de carácter ilegal, sin necesidad de dirigirse a todos y cada uno de los editores, puede resultar ventajosa para el afectado en muy diversos supuestos. Pensemos en un contenido ilegal — por ejemplo, un vídeo íntimo publicado sin permisoque ha sido publicado en numerosas páginas, algunas de las cuales se alojan en servidores extranjeros. Si bien el afectado español quizá no puede acudir a todos y cada uno de los editores responsables, sí podría esgrimir la ilegalidad ante el buscador alojado en España o en la Unión Europea, para que haga inaccesible dicho contenido conforme a las disposiciones domésticas. De este modo, su derecho al olvido se verá en gran medida salvaguardado.

En conclusión, frente a los contenidos de carácter ilegal el derecho al olvido se encuentra suficientemente garantizado. Su materialización pasará por acudir a la vía judicial oportuna para ver protegido el derecho vulnerado, normalmente el honor, la intimidad o la propia imagen. Declarada la ilegalidad del contenido, el órgano jurisdiccional ordenará al editor su efectiva retirada de Internet. A partir de ese momento, y con la sentencia declarativa de ilegalidad, el afectado podrá exigir a los buscadores y otros intermediarios de la sociedad de la información la efectiva retirada o cancelación de resultados, enlaces o formas de acceso al contenido, so pena de responder personalmente por dichos contenidos. Además, si el carácter ilegal de los contenidos resulta manifiesto, no será precisa sentencia o resolución alguna para solicitar al buscador la retirada del contenido de su lista de resultados.

18 Este sistema de responsabilidad ha sido importado de Estados Unidos, donde se conoce como el sistema de notice and get down. Para un certero análisis de la jurisprudencia comunitaria sobre la cuestión, resulta interesante: De Verda y Beamonte, J. R. (2014). «Responsabilidad del gestor del motor de búsqueda por los contenidos por la indexación y almacenamiento de datos contenidos en sitios de Internet», Actualidad Jurídica Iberoamericana, núm. 1, pp. 251-258.

19 Así lo ha interpretado la jurisprudencia del TS, entre otras, en sus SSTS, Sala $1^{\mathrm{a}}$, de 9 de diciembre de 2009, caso «putasgae.org», y de 10 de febrero de 2011, caso «alasbarricadas.com». 


\section{EL DERECHO AL OLVIDO RESPECTO DE CONTENIDOS LEGALES}

\section{1. ¿De qué supuestos estamos hablando?}

Pasemos a analizar ahora el derecho al olvido respecto de los contenidos cuya publicación en Internet fue, en principio, inocua, cuando no incluso exigida por una norma jurídica, pero que el interesado, pasado el tiempo, preferiría ver eliminados de Internet ${ }^{20}$. Normalmente, los contenidos que pretenden suprimirse son informaciones pretéritas, cuya publicación estuvo justificada en un momento dado del pasado, pero que han perdido actualidad, y cuya inmediata disponibilidad en Internet el interesado considera excesivamente gravosa. Máxime cuando dichos contenidos perjudiciales y extemporáneos aparecen como los primeros resultados ofrecidos por un buscador de Internet al buscar información sobre un determinado sujeto. En nuestro país, las publicaciones que más frecuentemente han suscitado la petición de olvido son de dos tipos: noticias de periódicos contenidas en hemerotecas, cuya digitalización las mantiene siempre accesibles; y resoluciones y avisos judiciales y administrativos, cuya publicación en boletines oficiales muchas veces es preceptiva a tenor de la normativa aplica$b^{21}$. Es oportuno recordar que la exigencia de cancelación o borrado de datos o informaciones perjudiciales del pasado no es una cuestión novedosa en nuestro ordenamiento jurídico, que contempla figuras como la cancelación de antecedentes penales o la anonimización de las sentencias judiciales y otras resoluciones administrativas antes de ser publicadas, con la pretensión de garantizar al sujeto su derecho a la intimidad, a la reinserción, al libre desarrollo de su personalidad, etc. ${ }^{22}$ Los motores de búsqueda y la memoria total de Internet, sin embargo, han

20 «Al hacer esto - explica el Abogado General en el caso Costeja- un interesado busca impedir que información potencialmente perjudicial sea conocida por parte de los usuarios de Internet, o está expresando su deseo de que esa información sea condenada al olvido, aun cuando la información de que se trate haya sido publicada legalmente por terceros». Conclusiones del Abogado General, apartado 102.

21 En ocasiones, la publicación está referida a materias «tan sensibles como la publicación de indultos, condenas, o la concesión de subvenciones a drogodependientes o víctimas de violencia doméstica, con identificación de sus beneficiarios». Rallo LOMBARTE, A. (2010). «El derecho al olvido y su protección a partir de la protección de datos», Telos: Cuadernos de comunicación e innovación, núm. 85 , p. 105.

22 Si bien Internet y los buscadores han situado este problema del olvido en un primer plano, es oportuno recordar que ya tradicionalmente «nuestro ordenamiento jurídico ha contemplado varias situaciones en las que se exige el olvido de hechos pasados, ya que su recuerdo supondría una hipoteca para el futuro de determinadas personas. Por ejemplo, los individuos que en el pasa- 
puesto en jaque dichos bienes jurídicos, al permitir un acceso permanente y universal a cualquier información pretérita, con el sencillo procedimiento de escribir el nombre del afectado en el buscador.

Si la huella o rastro digital dejada por estas noticias o resoluciones estuvo justificada en un momento determinado, hacer la misma indeleble en Internet puede en ocasiones resultar injusto. Así, resulta razonable que pasado un tiempo el afectado pretenda impedir la difusión o indexación en buscadores de información referida a su persona, «amparándose en su voluntad de que la misma no sea conocida por los internautas cuando considere que puede perjudicarle o desea que sea olvidada, aunque se trate de una información publicada lícitamente por terceros ${ }^{23}$.

Caso paradigmático de este deseo de borrar un contenido legal pero ya carente de actualidad e interés es el del señor Costeja. En el año 1998 el Diario La Vanguardia publicaba — por orden de la Tesorería de la Seguridad Social- dos anuncios relativos a una subasta de inmuebles del señor Costeja, para hacer frente a ciertos impagos con la Seguridad Social. Dicha publicación, aun pudiendo resultar incómoda para el perjudicado, era plenamente legal. Pues bien, al introducir en el buscador de Google el nombre del señor Costeja más de diez años después, todavía aparecían entre los primeros resultados los anuncios de subasta por impago, lo que evidentemente afectaba a la intimidad y el honor del citado empresario. Con la idea de eliminar dichos resultados, referidos a una cuestión ya resuelta y carente de cualquier interés público más de una década después del embargo, el señor Costeja solicitó tanto a La Vanguardia como a Google la retirada del contenido y los enlaces, respectivamente. Desoída su solicitud tanto por el diario catalán como por el buscador americano, el señor Costeja interpuso una reclamación ante la AEPD, que estimó su pretensión en relación con Google, al tiempo que la desestimó en relación con La Vanguardia ${ }^{24}$. Google interpuso un recurso ante la Audiencia Nacional, que antes de resolver sobre el fondo del asunto trasladó una serie de cuestiones prejudiciales al Tribunal de Justicia de la Unión Europea (en adelante, TJUE), en relación con la correcta interpretación

do delinquieron tienen un interés real y legítimo de cancelar sus antecedentes; un derecho a que se olvide su pasado para reintegrarse en la sociedad y edificar sin trabas su futuro». Simón CASTELlano, P. (2012). El régimen constitucional..., op. cit., p. 116. Sobre la tensión entre el principio de publicidad procesal y el derecho al olvido de informaciones judiciales, véase: CERNADA BADÍA, R. (2013). «El derecho al olvido judicial en la red», Libertad de expresión e información en Internet, Madrid, Centro de Estudios Políticos y Constitucionales, pp. 521-541.

23 Cotino Hueso, L. (2014). «La STJUE del caso Goolge vs AGPD de 2014. Algunos olvidos y otras tendencias negativas respecto de las libertades informativas en Internet», Valencia, Documento online, p. 4. Disponible en: http://www.uv.es/seminaridret/sesiones2014/google/ ponenciacotino.pdf (última visita: 01.02.2015).

24 Resolución 898/2010 AEPD, de 24 de mayo. 
de la normativa comunitaria. Las preceptivas conclusiones del Abogado General, publicadas el 25 de junio de 2013, se mostraron abiertamente contrarias al derecho al olvido. Empero, y rompiendo el tradicional seguidismo del Tribunal respecto de las conclusiones de los Abogados Generales, la STJUE de 13 de mayo se mostró favorable al mismo, y reconoció la obligación de Google de retirar el acceso a determinados contenidos para garantizar así el conocido como derecho al olvido ${ }^{25}$. El 29 de diciembre de 2014 la Audiencia Nacional pronunció su fallo sobre el caso Costeja, aplicando los criterios ofrecidos por el TJUE y reconociendo a Mario Costeja su derecho a exigir la retirada de los enlaces del buscador americano $^{26}$.

El caso del señor Costeja, que ha terminado constituyendo el leading case de la jurisprudencia comunitaria sobre el derecho al olvido, no es precisamente un caso aislado o extraordinario. De hecho, desde el año 2007 el número de quejas y denuncias ante la AEPD reclamando la cancelación de datos y el derecho al olvido en Internet no ha hecho sino aumentar ${ }^{27}$. Sin embargo, ha sido tras la sentencia del TJUE reconociendo la legitimidad de la pretensión del señor Costeja, cuando la cuestión del derecho al olvido respecto de contenidos legales se ha presentado con sus verdaderas dimensiones: Google ha recibido en pocas semanas en torno a cien mil solicitudes de cancelación de datos ${ }^{28}$.

25 STJUE (Gran Sala) de 13 de mayo de 2014 en el asunto C-131/12, en el procedimiento entre Google Spain, S. L., Google Inc. contra la Agencia Española de Protección de Datos y Mario Costeja González. Azurmendi encuentra una causa de esta diversidad de criterios en la crisis diplomático-comunicativa originada por las revelaciones de Edward Snowden, con el consiguiente replanteamiento de la política de protección de datos en la Unión Europea. AzURMENDI, A. (2015): «Por un derecho al olvido para los europeos: aportaciones jurisprudenciales de la Sentencia del Tribunal de Justicia Europeo del caso Google Spain y su recepción por la Sentencia de la Audiencia Nacional Española de 29 de diciembre de 2014», Revista de Derecho Político, núm. 92, pp. 275-276.

26 SAN 5129/2014, de 29 de diciembre. En enero de 2015 la Audiencia Nacional notificó las primeras dieciocho sentencias conectadas con el derecho al olvido, catorce de las cuales desestiman los recursos de Google y reconocen el derecho de los particulares a la retirada de los enlaces. A lo largo del primer trimestre de 2015, se han sucedido diferentes sentencias en la misma dirección, con unos fundamentos jurídicos prácticamente idénticos. En las contadas ocasiones que la Audiencia ha resuelto a favor de Google, se ha denegado el derecho al olvido debido a que el particular no aportó evidencias suficientes sobre los enlaces o las páginas web presuntamente perjudiciales. A título ejemplificativo, pueden consultarse las SSAN 5241/2014, de 30 de diciembre, y 5198/2014, de 29 de diciembre. En otros casos, se ha fallado a favor de Google reconociendo que su obligación se limita a retirar los resultados de las búsquedas asociadas al nombre del afectado, y no a otros términos de búsqueda (así, la SAN 5252/2014, de 29 de diciembre).

27 Memoria Anual 2013, Madrid, Agencia Española de Protección de Datos, 2014, p. 31.

28 «Google, perdido en la aplicación del derecho al olvido», Diario El Mundo, 9.9.2014. Disponible en: http://www.elmundo.es/tecnologia/2014/09/09/540f548ee2704e32188b4588. 
Si el conflicto de derechos en materia de olvido de contenidos ilegales era sencillo de resolver, cuando los contenidos son legales la ponderación se torna mucho más espinosa. Así lo acredita, sin ir más lejos, la llamativa divergencia entre las Conclusiones del Abogado General y la Sentencia del TJUE en el caso Costeja. Veamos cuáles son los principales interrogantes jurídicos que se plantean y cómo han sido abordados por la jurisprudencia y la doctrina ${ }^{29}$.

\section{2. ¿Resulta aplicable la normativa de protección de datos española?}

Al hablar de los contenidos ilegales —injurias, calumnias, amenazasdecíamos que el afectado podía alegar su derecho al honor, a la intimidad, a la propia imagen, a la dignidad, etc., obteniendo así una sentencia favorable y exigiendo la retirada del contenido. Sin embargo, cuando los contenidos han sido compartidos en Internet de manera legal, el único derecho que puede esgrimir para solicitar la retirada es el derecho a la protección de datos. Este derecho - contenido en estado germinal en el artículo $18.4^{\circ} \mathrm{CE}$, y reconocido como derecho independiente a partir de la STC 292/2000, de 30 de noviembre- ha sido desarrollado en nuestro país por la Ley Orgánica 15/1999, de 13 de diciembre, de Protección de Datos de Carácter Personal (LOPD) ${ }^{30}$. Si bien esta norma es relativamente reciente, no hay que perder de vista que al tiempo de su aprobación Internet se hallaba todavía en un estado muy incipiente, y algunas de las realidades que hoy más preocupan en materia de protección de datos en la Red

html (última visita: 01.02.2015). Conforme a los datos ofrecidos por la propia compañía, desde mayo de 2014 Google ha recibido 244.850 solicitudes y evaluado para su retirada un total de 888.091 direcciones de Internet. El 41,1\% de las URLs ha sido retirada. Datos obtenidos del Informe de Transparencia de Google, disponible en: http://www.google.com/transparencyreport/ (última visita: 24.04.2015)

29 A lo largo de las siguientes páginas se hará reiterada referencia a la STJUE del caso Costeja, y muy escasa a la jurisprudencia doméstica emanada por la Audiencia Nacional. Ello obedece a la práctica identidad de razonamientos esgrimidos y criterios aplicados por ambos tribunales. Habida cuenta del liderazgo del TJUE en esta materia, nos ha parecido más oportuno tomar como referente la resolución de dicho órgano jurisdiccional. Para un estudio sobre los matices con los que la STJUE ha sido recibida inicialmente en la Audiencia Nacional, véase: AzURMENDI, A. (2015): «Por un derecho al olvido para los europeos...», op. cit.

${ }^{30}$ La regulación española traspone a nuestro ordenamiento las disposiciones de la Directiva 95/46/CE del Parlamento Europeo y del Consejo, de 24 de octubre de 1995, relativa a la protección de las personas físicas en lo que respecta al tratamiento de datos personales y a la libre circulación de esos datos. Para un resumen del origen doctrinal y jurisprudencial del derecho a la protección de datos personales, resulta interesante: Garriga Domínguez, A. (2012). Fundamentos éticos y jurídicos de las TIC, Cizur Menor, Thomson Reuters-Aranzadi, pp. 74-78. 
- tales como las redes sociales, la responsabilidad de los buscadores, o el rastro digital — todavía no eran una realidad asentada en aquel entonces ${ }^{31}$. Por ello, y aún ofreciendo criterios de decisión válidos, la LOPD resulta en muchos casos insuficiente para resolver las cuestiones más complejas, carencia que se ha colmado con una amplia tarea interpretativa de la AEPD y con la aprobación de su Reglamento de desarrollo (en adelante, RLOPD) en $2007^{32}$. Este margen de interpretación ocasiona que a veces su aplicación sea algo impredecible, como se evidenció en el caso Costeja, donde el Abogado General y el TJUE llegaron a conclusiones diametralmente opuestas aplicando idéntico Derecho sustantivo.

A los efectos del presente estudio, hay que tener en consideración las siguientes previsiones de la LOPD y de la Directiva 95/46/CE: se considera dato personal cualquier información sobre una persona física identificada o identificable ${ }^{33}$; la inclusión de un dato personal en una página web, así como su recogida, grabación, conservación o cesión, es un tratamiento de datos, sujeto a las previsiones de la $\mathrm{LOPD}^{34}$; el responsable del tratamiento será quien decida sobre la finalidad, contenido y uso del tratamiento de los datos ${ }^{35}$; el interesado deberá dar su consentimiento para el tratamiento de sus datos personales ${ }^{36}$; dicho tratamiento sólo podrá hacerse sin consentimiento cuando concurran algunas de las causas previstas por Ley ${ }^{37}$; el tratamiento de los datos queda sujeto a los principios de temporalidad y pertinencia, de modo que cuando dejen de ser pertinentes o necesarios deberán ser eliminados ${ }^{38}$; el interesado tiene derecho de acceso, rectificación, cancelación y oposición al tratamiento de sus datos personales ${ }^{39}$.

31 Si este juicio es acertado en relación con la Ley española, de 1999, resulta aún más certero respecto de la normativa europea, inspiradora de la LOPD. Como señala el Abogado General Jääskinen en sus Conclusiones, «la presente petición de decisión prejudicial se ve afectada por el hecho de que, cuando la Comisión elaboró la propuesta de Directiva, en 1990, Internet, en el sentido de la actual World Wide Web, no existía, ni tampoco existían motores de búsqueda. En el momento de aprobación de la Directiva, en 1995, Internet apenas había comenzado y los primeros y rudimentarios motores de búsqueda comenzaban a surgir, pero nadie podía prever cuán profundamente iba a revolucionar el mundo». Conclusiones del Abogado General, apartado 10.

32 Real Decreto 1720/2007, de 21 de diciembre, por el que se aprueba el Reglamento de desarrollo de la Ley Orgánica 15/1999, de 13 de diciembre, de protección de datos de carácter personal.

33 Art. 3.a LOPD (2.a de la Directiva 95/46/CE).

34 Art. 3.c LOPD (2.b de la Directiva 95/46/CE). Así lo declaró inequívocamente la STJUE Lindqvist, apartados 25 a 27.

35 Art. 3.d LOPD (2.d de la Directiva 95/46/CE).

36 Art. 6 LOPD (7 de la Directiva 95/46/CE).

37 Art. 6.2 LOPD (7.b-e de la Directiva 95/46/CE).

38 Art. $4.1^{\circ}$ y $5^{\circ} \operatorname{LOPD}\left(6.1^{\circ}\right.$.b, c y e de la Directiva 95/46/CE).

39 Arts. 5.1 ${ }^{\circ}$.e y 17 LOPD (arts. 12 y 14 de la Directiva 95/46/CE). 
De las afirmaciones precedentes se extrae una primera conclusión: la aplicabilidad material de la normativa de protección de datos española a los conflictos relacionados con el derecho al olvido en Internet. En efecto, una página web con información u opiniones sobre personas concretas es un fichero sujeto a la normativa de protección de datos, como tienen dicho tanto la Audiencia Nacional como la AEPD ${ }^{40}$.

Sentado lo anterior, y considerando el carácter eminentemente transnacional de Internet, surge inmediatamente la pregunta sobre la aplicabilidad territorial de la legislación de protección de datos ${ }^{41}$. El artículo 2.a LOPD establece que la legislación española será de aplicación a «todo tratamiento de datos de carácter personal cuando el tratamiento sea efectuado en territorio español en el marco de las actividades de un establecimiento del responsable del tratamiento ${ }^{42}$. Esta previsión sitúa bajo la normativa española a aquellos editores con sede en España — medios de comunicación online, boletines oficiales, etc.—, así como a los perfiles de redes sociales y portales colaborativos con una oficina en nuestro país -Facebook, Tuenti, etc.

En cuanto a los buscadores, y en particular a Google, tanto la STJUE como el Abogado General entendieron que quedan sujetos a la legislación de un Estado cuando tienen en su territorio oficinas destinadas a vender espacios publicitarios. En el caso Costeja, Google argumentó que su servicio de buscador no está situado en España, y que por ello la legislación española no le resultaba de aplicación ${ }^{43}$. No obstante, ni el Tribunal ni el Abogado General Jääskinen aceptaron esa distinción entre gestor de búsqueda (Google Inc.) y gestor de publicidad (Google Spain), valorando la indisociable ligazón entre las actividades de ambas empresas ${ }^{44}$. Por lo tanto, cuando un buscador tenga su sede en España, o bien mantenga en nuestro país una oficina o sucursal con una actividad vinculada indisociablemente al buscador — como es el caso de Google Spain, que ges-

${ }^{40}$ Valga mencionar, por todas, la SAN 4029/2003, de 24 de enero, F. J. $3^{\circ}$, y la Resolución de la AEPD 1215/2011, de 30 de mayo.

41 Una explicación detallada de aplicabilidad territorial de la normativa española puede consultarse en: Simón Castellano, P. (2012). El régimen constitucional..., op. cit., pp. 194 y ss.

42 El artículo es una trasposición casi literal del artículo 4 de la Directiva 95/46/CE.

43 Sobre la argumentación de Google para rechazar la aplicabilidad de la legislación española, véase: Rallo Lombarte, A. (2014). El derecho al olvido en Internet, Madrid, Centro de Estudios Políticos y Constitucionales, pp. 137 y ss.

44 En este sentido, afirma el párrafo 57 STJUE: «Pues bien, toda vez que dicha presentación de resultados está acompañada, en la misma página, de la presentación de publicidad vinculada a los términos de búsqueda, es obligado declarar que el tratamiento de datos personales controvertido se lleva a cabo en el marco de la actividad publicitaria y comercial del establecimiento del responsable del tratamiento en territorio de un Estado miembro (...)». 
tiona los espacios publicitarios en el motor de búsqueda-, quedará vinculado a la normativa nacional de protección de datos ${ }^{45}$.

\section{3. ¿Quién es el responsable del tratamiento?}

Avanzando en nuestro análisis, es preciso preguntarse quién es el responsable del fichero conforme a lo previsto en el artículo 3.d LOPD (2.d de la Directiva), que define al responsable del fichero como la «persona física o jurídica, de naturaleza pública o privada u órgano administrativo, que decida sobre la finalidad, contenido y uso del tratamiento». Evidentemente, un primer responsable es el editor de la página web, por cuanto que es él quien ha elaborado o reproducido la información y la ha compartido en la Red.

Lo que resulta más espinoso, sin embargo, es determinar si el buscador de Internet — que localiza la información y la ofrece a los internautas - también ha de ser considerado responsable del tratamiento. A esta pregunta se han ofrecido dos respuestas contradictorias.

Hay quien afirma que los buscadores son responsables del tratamiento de datos, ya que su actividad se ajusta a la definición legal de responsable contenida en el mencionado artículo 3.d. Desde esta posición, se afirma que no cabe duda de que el buscador localiza, indexa, almacena, organiza y presenta los datos, decidiendo sobre la finalidad y uso del tratamiento, por lo que debe ser considerado responsable del tratamiento. Un segundo argumento que sostiene esta tesis de la responsabilidad del buscador se centra en los efectos del buscador, que multiplica la difusión de un determinado contenido ${ }^{46}$. Mientras que sin la mediación de un buscador un contenido en la Red tiene una difusión limitada, y es fácilmente sepultado entre millones de contenidos, la actuación del buscador multiplica la difusión del citado contenido, vinculándolo al nombre del afectado y dotándole de un potencial negativo difícil de valorar. De ello se deriva que la acción del buscador — por muy «ciega» o «neutral» que se pretenda- tiene

45 Boix Palop subraya con acierto que la normativa española podría ser de aplicación aun cuando Google no tuviera un establecimiento en España, atendiendo a la doctrina contenida el artículo 8 de la Carta de Derechos Fundamentales de la UE. Efectivamente, «el mero hecho de que una afección se produzca en territorio español (...) es a buen seguro suficiente (...) para que se reconozca jurisdicción a la instancia territorial donde sea más sentido el daño o efecto y desde donde sea más factible su reparación y la defensa de sus intereses jurídicos por parte del ciudadano afectado». Borx Palop, A. (2015). «El equilibro entre los derechos del artículo 18 de la Constitución, el derecho al olvido y las libertades informativas tras la Sentencia Google», Revista General de Derecho Administrativo, núm. 38, p. 9.

46 Rallo Lombarte, A. (2010). «El derecho al olvido y su protección...», op. cit., pp. 106 y ss. 
unos efectos específicos y poderosos sobre los datos del afectado, de los que el buscador debe en consecuencia responder. Esta línea argumental lleva a los partidarios de esta opción a concluir que el buscador es un verdadero responsable del tratamiento, como hizo la STJUE en el caso Costeja $\mathrm{a}^{47}$.

Desde tribunas contrarias, se han alzado voces que cuestionan la aplicabilidad de esta responsabilidad al buscador, señalando que existe una diferencia entre realizar un tratamiento de datos — cosa que innegablemente hace un buscadory ser responsable de dicho tratamiento ${ }^{48}$. Los argumentos esgrimidos desde esta posición son los siguientes: un buscador no trata los datos personales en cuanto tales, sino en cuanto información contenida en Internet, sin distinguir los datos personales de los que no lo son; un buscador no tiene poder editorial sobre los contenidos, simplemente permite localizar contenidos ya existentes en la Red; imponer al buscador la responsabilidad sobre los datos que «canaliza» resultaría desproporcionado, toda vez que sus sistemas de tratamiento de datos son ciegos — meramente técnicos_- y no le permiten conocer o interpretar el contenido de la comunicación; entender que el buscador es responsable el tratamiento llevaría a conclusiones desproporcionadas y absurdas, como por ejemplo la de deducir que todos los buscadores actúan en la ilegalidad, en la medida en que no han solicitado permiso para indexar datos personales. La idea latente en todos estos argumentos es la misma: el buscador es un mero intermediario en la Red, una herramienta para localizar información sin capacidad decisoria sobre la misma ${ }^{49}$.

47 El párrafo 80 de la STJUE resulta elocuente en este sentido: el tratamiento de datos personales que efectúa un motor de búsqueda «puede afectar significativamente a los derechos fundamentales de respeto a la vida privada y de protección de datos personales cuando la búsqueda realizada sirviéndose de ese motor de búsqueda se lleva a cabo a partir del nombre de una persona física, toda vez que dicho tratamiento permite a cualquier internauta obtener mediante la lista de resultados una visión estructurada de la información relativa a esta persona que puede hallarse en Internet, que afecta potencialmente a una multitud de aspectos de su vida privada, que, sin dicho motor, no se habrían interconectado o sólo podrían haberlo sido muy difícilmente y que le permite de este modo establecer un perfil más o menos detallado de la persona de que se trate. Además, el efecto de la injerencia en dichos derechos del interesado se multiplica debido al importante papel que desempeñan Internet y los motores de búsqueda en la sociedad moderna, que confieren a la información contenida en tal lista de resultados carácter ubicuo».

48 Como resume Rallo Lombarte, «la neutralidad del servicio de búsqueda constituye, sin duda, uno de los principales asideros sobre los que Google argumenta su falta de responsabilidad sobre el tratamiento de datos que implica la actividad del buscador. Por el contrario, la capacidad del webmaster de decidir sobre la indexación de los contenidos de su web le convertiría en responsable directo y, en consecuencia, debería garantizar el cumplimiento de la normativa de protección de datos». Rallo Lombarte, A. (2014). El derecho al olvido en Internet, op. cit. p. 140.

49 Estos argumentos fueron esgrimidos por el propio TJUE en su STJUE de 23 de marzo de 2010 (asuntos acumulados C-236/08 y C-238/08 Google France c. Louis Vuitton), donde se 
En la medida en que el buscador actúa como un mero intermediario, carece de medios para modificar la información, y no decide sobre los datos, no debe imponérsele la responsabilidad sobre los mismos. Esta opinión fue la mantenida por el Abogado General en sus conclusiones sobre el caso Costeja, y ha sido sostenida desde muy solventes sectores doctrinales ${ }^{50}$.

\section{4. ¿Concurren intereses legítimos que justifican un tratamiento sin consentimiento del afectado?}

Pasemos a la cuestión del consentimiento. La ley exige, para el tratamiento de los datos personales, del consentimiento del interesado (art. 6 LOPD y 7.a de la Directiva). Evidentemente, en los casos que nos ocupan, en los que el afectado reclama el derecho al olvido, hay que presumir que no ha prestado su consentimiento para el tratamiento, o, en los supuestos en que lo hubiera prestado, quiere revocarlo. Entre las informaciones nunca consentidas podemos imaginar anuncios de subastas, multas de tráfico, sentencias judiciales, noticias u opiniones incómodas, etcétera. Entre las segundas, reportajes o exclusivas de los que el interesado se arrepiente o declaraciones que querría corregir. ¿Puede el responsable del fichero mantener el tratamiento de los datos sin el consentimiento del afectado, aun cuando éste le solicite la retirada o cancelación de los datos? La LOPD prevé en su artículo $6.2^{\circ}$ diversos supuestos en los que puede prescindirse del consentimiento del afectado. Entre los mismos, la Ley señala que no será preciso el consentimiento cuando «los datos figuren en fuentes accesibles al público y su tratamiento sea necesario para la satisfacción del interés legítimo perseguido por el responsable del fichero o por el del tercero a quien se comuniquen los datos».

En la concreta aplicabilidad de esta causa de justificación, de esta excepción a la necesidad del consentimiento, se dirime la existencia del derecho al olvido. Si el responsable del fichero — el editor de la web en todo caso, o el buscador en

señala que para gozar de la exclusión de responsabilidad reconocida en la Directiva 2000/31/CE la actividad del prestador de servicios de la información debe tener una naturaleza meramente técnica, automática y pasiva, lo que implica que el prestador «no tenga conocimiento ni control de la información transmitida o almacenada» (párrafo 113).

50 Conclusiones del Abogado General, apartados 70 y ss. En el apartado 89 el Abogado General Jääskinen afirma: «A mi juicio, el proveedor de servicios de motor de búsqueda en Internet no puede ni jurídicamente ni de hecho cumplir las obligaciones del responsable del tratamiento establecidas en los artículos 6, 7 y 8 de la Directiva, en relación con los datos personales contenidos en las páginas web fuente alojadas en servidores de terceros. Por lo tanto, una interpretación razonable de la Directiva requiere que no se considere que el proveedor de servicios se encuentra con carácter general en esa posición». 
caso de adoptar la interpretación que le considera un verdadero responsable del tratamiento - demuestra que su contenido sirve a un interés legítimo propio o de un tercero, podrá mantener la información en Internet. Si, por el contrario, no acredita la existencia de dicho interés, deberá retirar el contenido para no ser responsable de un tratamiento de datos ilegal.

¿Qué intereses legítimos pueden aducir el editor o el buscador?

El editor podrá alegar, como intereses propios, su derecho a la información o a la libertad de expresión: ofrecer información u opinión en la Red es un ejercicio de los derechos comunicativos protegidos por la Constitución. Igualmente, el editor podrá alegar idénticos derechos como intereses legítimos de terceros: los internautas que tienen derecho a acceder a los contenidos incluidos en la Red. Hoy en día el medio de acceso a la información por antonomasia en el Primer Mundo es Internet, de modo que poner a disposición del público determinada información a través de dicho canal responde a un interés general innegable. A la hora de valorar si dicha información o comunicación tiene un carácter legítimo, será oportuno valorar su contenido, fundamentalmente conforme a los criterios sentados por el Tribunal Constitucional en su jurisprudencia sobre los derechos comunicativos: la veracidad y el interés público. Mientras una información sea veraz, habrá que presumir su carácter protegido por la Constitución (art. 20.1 ${ }^{\mathrm{o}}$ d) $)^{51}$; y cuanto más interés público revista la comunicación, mayor grado de protección merecerá ${ }^{52}$.

En cuanto al buscador — si se acepta que es responsable del tratamiento, cuestión que como hemos visto no es en absoluto pacífica-, un primer interés propio y legítimo que puede alegar es el derecho a la libertad de empresa, reconocido en el artículo $38 \mathrm{CE}$. Junto con este derecho, somos de la opinión de que el buscador podrá alegar asimismo un interés ajeno legítimo: el mismo que podía alegar el editor de la página, y que no es otro que los derechos comuni-

51 STC 68/2008, de 23 de junio, F. J. 3º. Como apunta Catalá, «el principio de veracidad demanda una labor de comprobación de los hechos. Esta comprobación comporta un juicio de razonabilidad. Es decir, a la vista de la investigación efectuada razonablemente se ha de concluir que los hechos son ciertos». Catalá I Bas, A. H. (200I). Libertad de expresión e información. La jurisprudencia del TEDH y su recepción por el Tribunal Constitucional, Valencia, Ediciones Revista General de Derecho, p. 115.

52 Como tiene dicho el TC, para valorar la efectiva concurrencia de interés público de una determinada información, habrá que tomar en consideración «las materias a que se refiere y las personas que en ello intervienen». STC 178/1993, de 31 de mayo, F. J. 2². Además, como ya advirtió el TEDH, el interés público no puede reducirse exclusivamente al interés político, sino que se extiende a otras cuestiones de interés general, cualquiera que sea su naturaleza (política, social, artística, cultural, deportiva, etc.). STEDH Thorgeir Thorgeirson c. Islandia, de 25 de junio de 1992, párrafo 64. 
cativos de los internautas. En la medida en que los usuarios suelen buscar información contenida en Internet a través de motores de búsqueda, los servicios del buscador forman parte casi insustituible del proceso de acceso a la información, y quedan por lo tanto protegidos también por el artículo $20.1^{\circ}$.a y d de la Constitución ${ }^{53}$. Abundando en este argumento, es oportuno subrayar que una de las dimensiones del derecho a la información es la dimensión investigadora, toda vez que resulta difícil ofrecer información veraz sin llevar a cabo una labor de investigación previa. A día de hoy, resulta indudable que los buscadores de Internet son una herramienta insustituible en la labor de investigación de informaciones, de lo que se concluye que sus actividades quedan subsumidas en el artículo $20.1^{\circ} \mathrm{CE}^{54}$. Esta es la opinión de un amplio sector doctrinal, que sostiene que «la garantía institucional reconocida clásicamente a los medios de comunicación social, que refuerza jurídicamente la posición de los medios, ya no solo debe atribuirse a éstos, sino que también debe reconocerse especialmente a determinados prestadores de servicios de la sociedad de la información», entre los que se entiende comprendido en un lugar muy privilegiado el buscador de Google, por su casi plebiscitaria utilización para la búsqueda de informaciones en la Red ${ }^{55}$.

53 Así lo reconoce explícitamente el Abogado General en los apartados 131 y 132 de sus Conclusiones. Estas son sus reflexiones: «en la sociedad de la información actual, el derecho a la búsqueda de información publicada en Internet mediante motores de búsqueda es una de las formas más importantes de ejercitar este derecho fundamental. (...) El derecho a la información de un usuario de Internet se vería comprometido si su búsqueda de información relativa a una persona física no generara resultados que ofrezcan un reflejo veraz de las páginas web relevantes, sino una versión bowdlerizada [adaptada según determinados intereses] de las mismas». Aunque el debate excede del objeto del presente trabajo, cabe plantearse si los buscadores de Internet podrían alegar el derecho instrumental a crear medios de comunicación. Este derecho ha sido reconocido por el TC al afirmar que el artículo $20.1^{\circ}$ al reconocer las libertades de expresión e información «consagra también el derecho a crear los medios de comunicación indispensables para el ejercicio de estas libertades». STC 31/1994, de 31 de enero. Si bien un buscador no es propiamente un medio de comunicación, indudablemente es una herramienta insustituible para acceder a la misma, con lo que no resulta osado reconocer a estos prestadores de servicios un verdadero derecho instrumental reconocido en el art. 20.1 ${ }^{\circ} \mathrm{CE}$.

54 Como ha destacado Martínez Sospedra, «la libertad de informar presupone la libertad de obtener la información. Por tanto, como no cabe información, y mucho menos información veraz, sin previa búsqueda y obtención de la misma se sigue que forma parte del contenido esencial de aquella la libertad de investigar». MARTínez Sospedra, M. (1993). Libertades públicas, v. I, Valencia, Fundación Universitaria San Pablo CEU, p. 259.

55 Cotino Hueso, L. (2014). «La STJUE del caso Google vs AGPD de 2014...», op. cit., p. 7. Y algo más adelante resume el mismo autor: «Aquí se ha sostenido que los grandes prestadores de servicios e intermediarios de Internet deben contar con una especial protección constitu- 
Desde otras tribunas — lo hace la propia STJUE en el caso Costeja — se hace hincapié en la naturaleza comercial de los buscadores, rechazando que los mismos puedan quedar amparados por los derechos comunicativos ${ }^{56}$. Si bien se admite que un buscador al hacer un tratamiento de datos ejerce un interés económico legítimo, se excluye que su actividad quede amparada por los derechos comunicativos. Desde esta perspectiva, se excluye a los buscadores de la «excepción periodística», que justifica sin embargo que un editor haga un tratamiento de datos sin consentimiento del afectado ${ }^{57}$. Esta fue la solución adoptada tanto por la AEPD como por la STJUE en el caso Costeja, cuando entendieron que Google sí estaba obligado a retirar los enlaces al contenido, al tiempo que el editor —el diario La Vanguardia - no debía retirar de la web los anuncios de la subasta ${ }^{58}$. En efecto, la STJUE entendió que el buscador no ejerce derecho fundamental alguno, quedando su actividad justificada exclusivamente por un interés empresarial y protegida por el derecho a la libertad de empresa. Dicho interés crematístico y dicho derecho no justifican la vulneración del derecho a la protección de datos del interesado, por lo que salvo que concurra un claro interés público en una determinada información, el buscador deberá acceder a la pretensión de cancelación — derecho al olvido— del solicitante afectado ${ }^{59}$. Desde otro prisma, Simón Castellano excluye a los buscadores del ámbito de protección de los derechos comunicativos esgrimiendo su falta de «neutralidad», al presentar los resultados en función de un logaritmo concreto, de las preferencias del propio

cional, bajo los mismos fundamentos que esta intensa protección se ha otorgado a los medios de comunicación clásicos». Ibídem, p. 22.

56 En este sentido, el TJUE afirma en la sentencia: «vista la gravedad potencial de esta injerencia, es obligado declarar que el mero interés económico del gestor de tal motor en este tratamiento no la justifica» (párrafo 81).

${ }^{57}$ La argumentación del TJUE se contiene en el párrafo 85 de la sentencia: «el tratamiento por parte del editor (...) puede, en su caso, efectuarse con fines exclusivamente periodísticos y beneficiarse, de este modo (...) de las excepciones a los requisitos que la Directiva establece, mientras que ése no es el caso en el supuesto del tratamiento que lleva a cabo el gestor de un motor de búsqueda. De este modo, no puede excluirse que el interesado pueda en determinadas circunstancias ejercer los derechos (...) contra el gestor, pero no contra el editor de dicha página web».

${ }^{58}$ Como explica Rallo Lombarte, «la libertad de información sería predicable sólo de quienes publican noticias con datos personales pero no de los buscadores de Internet que estaría obligados, en su caso, a evitar la indexación de los mismos e impedir futuras captaciones». RALLO LOMBARTE, A. (2014). El derecho al olvido en Internet, op. cit., p. 185.

59 Conjugando los criterios ofrecidos por el TJUE y la jurisprudencia del TC, la SAN 5129/2014, de 29 de diciembre, dedica su Fundamento Jurídico Undécimo a exponer el conflicto entre la libertad de empresa y la protección de datos y cómo ha de resolverse. 
usuario, o incluso del dinero que los anunciantes ofrecen al buscador a cambio de privilegiar sus enlaces respecto de los de la competencia ${ }^{60}$.

Particularmente, nos decantamos por la primera interpretación, que entiende que los buscadores ejercen en su tarea los derechos comunicativos. Como ha denunciado Cotino Hueso con ocasión del pronunciamiento del TJUE, «detrás de esta corriente tendente a la no generalización de las libertades plenamente a Internet parece latir que los grandes prestadores de servicios tienen una finalidad económica que los aleja del mercado de las ideas, quedándose sólo en mercado» ${ }^{61}$. Sin embargo, el interés económico no excluye la aplicabilidad de las libertades informativas, como ya tienen dicho tanto la jurisprudencia europea como la nacional sobre la comunicación publicitaria, sin ir más lejos ${ }^{62}$. En cuanto a la objeción apuntada de la falta de neutralidad de los buscadores, pensamos que la misma sería perfectamente aplicable a cualquier medio de comunicación, ya que quien más quien menos privilegia unas informaciones respecto de otras en función de su línea editorial, de las preferencias de su público objetivo o de los intereses de sus anunciantes. Si a las empresas periodísticas tradicionales no se les exige esa «neutralidad» para entenderlas amparadas por los derechos reconocidos en el artículo $20.1^{\circ} \mathrm{CE}$, no se entiende por qué hay que exigírsela a los buscadores de Internet. Un último argumento que respalda la subsunción de los buscadores en el ámbito de los derechos del artículo $20.1^{\circ}$ es el de la coherencia. $\mathrm{Si}$, como la sentencia afirma, los buscadores realizan un tratamiento de datos específico y principal, que otorga a los mismos una gran difusión en la Red y por el que han de ser considerados responsables, resulta razonable ofrecerles las garantías jurídicas reconocidas a quien difunde mensajes por cualquier medio de difusión. Lo que no resulta coherente es afirmar que los buscadores realizan una actividad de difusión jurídicamente relevante a efectos de exigirles determinadas obligaciones, al tiempo que se niega dicha relevancia para excluirles del disfrute de ciertos derechos. Si son responsables de difundir información, deberán cumplir con todos sus deberes, pero también podrán disfrutar de todos sus derechos.

Por consiguiente, consideramos que a la hora de enjuiciar los intereses legítimos a los que sirve el buscador, no hay que ponderar exclusivamente el interés de carácter económico o comercial — protegido en el artículo $38 \mathrm{CE}$, dentro de

60 Simón Castellano, P. (2012). El régimen constitucional..., op. cit., pp. 176 y 177.

61 Cotino Hueso, L. (2014). «La STJUE del caso Google vs AGPD de 2014...», op. cit., p. 13.

${ }^{62}$ Como señaló el TEDH en su STEDH Casado Coca c. España de 24 de febrero de 1994, la distinción sobre la naturaleza — lucrativa o no- del fin perseguido por la comunicación no resulta relevante de cara a su subsunción dentro del ámbito de los derechos comunicativos. En este mismo sentido se pronuncia la STC 87/1987, de 2 de junio. 
la parte programática del texto constitucional—, sino también un interés esencial para la convivencia como es el acceso libre a la información y a las distintas opiniones, interés que ha cristalizado en los derechos fundamentales contenidos en el artículo $20.1^{\circ} \mathrm{CE}$, dentro de la parte dogmática de la Constitución ${ }^{63}$. De lo anteriormente expuesto se desprende — siempre en nuestra opinión- que tanto el buscador como el editor podrán invocar la causa de justificación prevista por la LOPD para tratar datos de un tercero sin su consentimiento, en la medida en que el tratamiento que efectúan — la puesta a disposición de determinadas opiniones o información en Internet - sirve a intereses legítimos. Concretamente, a los derechos comunicativos de los internautas, derechos esenciales para la creación de una opinión pública libre en un Estado democrático.

Sea de ello lo que fuere, la propia LOPD añade un punto más de indeterminación al señalar en su artículo $6.4^{\circ}$ que cuando «no sea necesario el consentimiento del afectado para el tratamiento de los datos de carácter personal, y siempre que una ley no disponga lo contrario, éste podrá oponerse a su tratamiento cuando existan motivos fundados y legítimos relativos a una concreta situación personal. En tal supuesto, el responsable de fichero excluirá del tratamiento los datos relativos al afectado». Parece que este inciso da cabida pues al ejercicio de los derechos de oposición y cancelación del afectado, derechos que le reconocen la posibilidad de exigir la eliminación de sus datos respecto de un fichero concreto, aun cuando no hubiera sido necesario recabar el consentimiento para el realizar el tratamiento. Y ello porque pretender el derecho al olvido en la Red de determinados contenidos puede obedecer a «un motivo fundado y legítimo, relativo a una concreta situación personal».

El tenor de este apartado $4^{\circ}$ parece devolvernos pues al punto inicial de nuestra reflexión: ¿qué derechos deben prevalecer? ¿Los derechos comunicativos y la libertad de empresa, o el derecho a la protección de datos personales?

Habida cuenta de esta indeterminación legal y jurisprudencial —comprensible debido a la novedad de las cuestiones que se sustancian en este debate- a nuestro parecer la solución a cada caso habrá que buscarla por el momento partiendo de los criterios de ponderación asentados por el TC en materia de derechos comunicativos, que son básicamente la veracidad y el interés público ${ }^{64}$. Esta es

63 Tal es la opinión del Abogado General en el caso Costeja, manifestada en el apartado 95 de sus Conclusiones.

64 Ya en el año 2007 el profesor Martínez Martínez apuntaba a estos criterios ante futuros conflictos entre el derecho a la protección de datos y los derechos comunicativos. MARTínez Martínez, R. (2007). «El derecho fundamental a la protección de datos: perspectivas», IDP: revista de Internet, Derecho y Política, núm. 5, p. 55. En idéntico sentido, véase: Simón CASTELLANO, P. (2012). El régimen constitucional..., op. cit., p. 128. 
la línea seguida por la AEPD en sus resoluciones más recientes, cuando afirma por ejemplo que «ningún ciudadano que no sea objeto de un hecho noticiable de relevancia pública tiene que resignarse a que sus datos se difundan en Internet sin poder reaccionar ni corregir su inclusión» ${ }^{65}$.

En relación con estos criterios, en Internet cobra una importancia esencial la cuestión del paso del tiempo. Y ello porque puede suceder que una información que en un momento concreto tuvo un gran interés público - interés que justificó su publicación-, con el transcurso de los meses o años pase a un segundo o tercer plano, perdiendo su actualidad y con ella su interés; o también que determinadas informaciones, totalmente veraces en el momento de su publicación, al cabo del tiempo se demuestran imprecisas, o, sencillamente, erróneas u obsoletas. El paso del tiempo, así, recomendará en ocasiones buscar un nuevo equilibrio en la ponderación de derechos, cambiando el centro de gravedad desde los derechos comunicativos al derecho a la protección de datos personales ${ }^{66}$. Esta idea es expresada por De Terwangne, cuando afirma: «el valor informativo de un caso inclina la balanza a favor del derecho a difundir a costa del derecho al olvido. Y en cuanto deja de tener valor como noticia, la balanza se inclina en la otra dirección» ${ }^{67}$. Tomemos como paradigma el caso Costeja, ciertamente ejemplificativo de lo que se viene diciendo: si unas semanas antes de producirse la subasta la información sobre la misma estaba plenamente justificada, ofrecer la información más de diez años después parece a todas luces desproporcionado ${ }^{68}$. Mientras que la información originaria — en la fecha en que fue publicada — era plenamente legítima, la misma información, rescatada por el motor de búsqueda una década después, sin el contexto oportuno o sin consideración alguna a la fecha en la que fue publicada, resulta a todas luces extemporánea ${ }^{69}$.

${ }^{65}$ Hernández Ramos, M. (2013). «El derecho al olvido digital en la web 2.0», op. cit., p. 28.

66 La STJUE se ocupa de la cuestión del paso del tiempo en los párrafos 93 y siguientes, señalando que el mismo puede ser determinante para que ciertos datos, publicados legalmente en su día, dejen de ser adecuados o pertinentes.

67 De Terwangne, C. (2012). «Privacidad en Internet...», op. cit., p. 56.

68 Para consultar otros ejemplos — nacionales y comparados - de clara pérdida de relevancia de una información por el paso del tiempo, véase: Azurmendi, A. (2015): «Por un derecho al olvido para los europeos...», op. cit. pp. 295-297.

69 Un sector doctrinal ha planteado la posibilidad de que el paso del tiempo opere en sentido inverso, dotando de interés público a informaciones que inicialmente no lo tenían o que dejaron de tenerlo, y por ello fueron objeto del derecho al olvido. En estos supuestos, que no resultan difíciles de imaginar, el derecho al olvido hurtaría del conocimiento general informaciones que podrían resultar importantes. BoIX PALOP, A. (20I5). «El equilibro entre los derechos...», op. cit., p. 32. 


\subsection{Resumiendo las posiciones existentes}

En las páginas precedentes hemos analizado las diferentes cuestiones jurídicas que el derecho al olvido respecto de contenidos legales suscita, ofreciendo las diferentes posturas que ante cada interrogante se han ensayado. A continuación se resumen sintéticamente las dos principales posiciones respecto a la existencia de dicho derecho, representadas respectivamente por la STJUE y por las Conclusiones del Abogado General en el caso Costeja.

Por un lado, cabe negar el derecho al olvido, optando por el mantenimiento de la información en la Red. Esta solución hace hincapié en la libertad de expresión e información en la Red, por encima de los derechos o intereses de las personas afectadas. Si se adopta esta postura, será necesario educar a los internautas para que valoren en su justa medida los resultados que ofrecen los buscadores, teniendo en cuenta la fecha de los hechos y el contexto en el que se produjeron. Por el contrario, puede reconocerse el derecho al olvido, y obligar a editores o buscadores a retirar una información o el acceso a la misma, en la medida en que ya no contribuye al debate público y debe ceder ante el derecho a la protección de datos del afectado. Esta opción parece más acorde con los principios de la normativa europea y nacional de protección de datos, especialmente con el derecho a la oposición y a la cancelación, así como con el principio de temporalidad y pertinencia en el tratamiento de los datos. Empero, la eliminación de esta información incómoda de la Red no está exenta de problemas: ¿qué sucede con las hemerotecas de los diarios, la mayoría de las cuales ya han sido digitalizadas y volcadas en la Red? ¿Habrá que borrarlas o hacerlas inaccesibles desde Internet definitivamente? ¿No entorpecerá esta medida el derecho a la información, en su dimensión investigadora? ¿No tiene derecho el internauta a saber lo que en un momento dado se opinaba o se informó sobre un tercero?

En el caso Costeja, tanto la AEPD como el TJUE se decantaron por la segunda opción, reconociendo el derecho al olvido y exigiendo que los buscadores retiren los enlaces a las páginas con información que afecte a los derechos de un tercero. Sin embargo, la AEPD negó la obligación del editor de retirar la información, extendiendo dicho deber exclusivamente al buscador, al ser el canal de difusión y acceso a la información más poderoso. De este modo, se admite que el editor mantenga el contenido, pero se restringe enormemente su difusión, al evitar que los buscadores indexen el mismo ${ }^{70}$. Esta decisión supone un alivio para

${ }^{70}$ En este sentido, señala la SAN 5129/2014, de 29 de diciembre, F. J.12: «Con carácter general y como reflexión previa al concreto juicio de ponderación de los derechos e intereses en conflicto que haremos más adelante, debe ponerse de manifiesto que la libertad de información, 
todos aquellos que han visto su intimidad o su honor afectados en la Red, otorgándoles la posibilidad de lavar su imagen y rehacer su reputación digital. La postura adoptada por el TJUE no está exenta de cuestionables efectos colaterales: impone a los buscadores la carga de valorar todas y cada una de las solicitudes de cancelación, y deja en sus manos el juicio acerca del interés público de cada información, así como la ponderación entre los derechos comunicativos del editor, buscador e internauta y el derecho a la protección de datos del afectado. De este modo, se lastra enormemente el trabajo de los buscadores, al tiempo que se les otorga un amplio poder decisorio sobre qué contenidos deben retirar y cuáles no. Esta decisión, como se ha denunciado tempranamente desde diferentes tribunas, resulta dudosamente proporcional; además, abre la puerta a la censura privada de contenidos en Internet, cuya indexación queda al albur del buen entendimiento del motor de búsqueda, erigido sin pretenderlo en árbitro de los intereses en liza, sobre los que tiene inexorablemente que decidir ${ }^{71}$.

Por su parte, el Abogado General no entendió exigible el derecho al olvido frente a los buscadores de Internet ${ }^{72}$. En primer lugar, por no considerarles responsables del tratamiento; y en segundo lugar — caso de que fueran responsables- por entender que su actividad está amparada en un interés legítimo ${ }^{73}$. En opinión del Abogado General, la persona molesta por un contenido de la Red que le afecte personalmente, deberá dirigirse al editor de dicha información, solicitándole bien la retirada del contenido; bien la adopción de algunas medidas tecnológicas que eviten su indexación por los buscadores. En cuanto a los buscadores, el señor Jääskinen entendió que si una información está en la Red, los

en principio, se encuentra satisfecha por su subsistencia en la fuente, es decir, en el sitio web donde se pública la información por el editor.»

${ }^{71}$ Este último es el principal inconveniente que Cotino Hueso encuentra en la sentencia: la «privatización» sobre la decisión de si un determinado contenido debe ser accesible en Internet. Estas son sus palabras: «el TJUE tampoco parece tener en cuenta el efecto que produce que el acceso efectivo a la información en Internet, instrumentado esencialmente a través de Google (...) quede condicionado a los intereses privados, ya sean los criterios de los afectados por la información que solicitan la retirada masiva de contenidos, ya sea de Google a la hora de estimar o no las solicitudes de retirada». Cơtino HuEso, L. (2014). «La STJUE del caso Google vs AGPD de 2014...», op. cit., pp. 8 y 9. En idéntico sentido alertan las Conclusiones del Abogado General, apartado 134; y Boix PAlop, A. (2015). «El equilibro entre los derechos...», op. cit., pp. 21 y 22.

${ }^{72}$ La jurisprudencia estadounidense se ha decantado por esta solución. Como ha señalado Touriño, en Estados Unidos «el debate del derecho al olvido es un tema resuelto y zanjado, por haber entendido el poder judicial estadounidense de manera reiterada que tratar de impedir la libre disposición de resultados de los buscadores chocaría frontalmente con los valores constitucionales» consagrados en la Primera Enmienda. Touriño, A. (2014). El derecho al olvido y a la intimidad en Internet, Madrid, Catarata, p. 42.

73 Conclusiones del Abogado General, apartados 89 y 137. 
buscadores tienen derecho a indexarla y ofrecerla, sin responder en absoluto de su legalidad ni tener obligación de valorarla ni retirarla de su lista de resultados. Como señalamos con anterioridad, el Abogado General entiende que los buscadores no deberían ser considerados propiamente «responsables del tratamiento», por lo que no cabría exigir frente a ellos el derecho de oposición o cancelación. Por otro lado, y a diferencia del TJUE, el Abogado argumenta que los buscadores son una garantía del ejercicio de los derechos comunicativos, con lo que caso de ser considerados responsables de tratamiento, tienen un interés legítimo en hacerlo, de modo que no necesitan el consentimiento de la persona afectada. El Abogado General subrayó que frente al interés de quien aspira al olvido digital, se alza el interés de quien busca información sobre ese sujeto, interés protegido por el derecho a la información. Permitir el derecho al olvido digital puede suponer, desde esta perspectiva, una restricción del derecho a la información del internauta, a quien se le ofrecerá una versión filtrada o acomodaticia del pasado del interesado, y no todos los resultados vinculados a su nombre que se encuentren en Internet. En cuanto a la obligación del editor de retirar la información, el Abogado General no realizó un juicio concreto, toda vez que la consulta de la AEPD no versaba sobre ese punto.

\section{ESTADO DE LA CUESTIÓN: MÁS DUDAS QUE CERTEZAS}

\subsection{La reacción de Google}

Tras la sentencia del TJUE Google, el principal buscador de Internet, ha establecido un procedimiento de «Solicitud de retirada de resultados de búsqueda», para hacer efectivo el derecho al olvido reconocido en la sentencia ${ }^{74}$. Junto con este procedimiento, el gigante americano ha creado un comité de expertos en la materia con el fin de reflexionar sobre la aplicación del derecho al olvido en Internet, entre los que se encuentran Eric Schmidt, ex presidente de Google, Jimmy Wales, director de Wikipedia, y José Luis Piñar, catedrático de Derecho Administrativo y ex director de la AEPD. En los tres meses siguientes al fallo

${ }^{74}$ La explicación del procedimiento de retirada puede consultarse en: Privacidad y Condiciones, Preguntas Frecuentes (https://www.google.es/intl/es/policies/faq/). Por su parte, la Solicitud de retirada está disponible en: https://support.google.com/legal/contact/lr_ eudpa? product = websearch\&hl=es (última visita: 01.02.2015). Otros motores de búsqueda con menor implantación en nuestro país también han adoptado medidas concretas para cumplir con la resolución. Es el caso del buscador Bing, de Microsoft, que en el siguiente enlace ofrece un formulario para solicitar la retirada de resultados de búsquedas: https:/www.bing.com/webmaster/ tools/eu-privacy-request com (última visita: 01.02.2015). 
del TJUE, Google recibió alrededor de ciento veinte mil solicitudes de cancelación de datos, lo que permite hacerse una idea de las enormes consecuencias jurídicas del pronunciamiento del tribunal europeo ${ }^{75}$. Para el buscador, uno de sus principales retos ahora radica en la gestión de tan ingente número de solicitudes, para lo que precisa de un cuerpo de expertos que enjuicie la oportunidad de cada solicitud, y resuelva si ha de ser atendida o no.

En la explicación del procedimiento de retirada de resultados, Google indica sobre qué bases realizará la ponderación de intereses en juego. La explicación que se ofrece a los interesados es la siguiente: «Al realizar esa solicitud, Google realizará una ponderación entre los derechos de privacidad de los usuarios y el derecho del público a conocer y distribuir información. Al evaluar su solicitud, Google examinará si los resultados incluyen información obsoleta sobre usted, así como si existe interés público por esa información (por ejemplo, Google puede negarse a retirar determinada información sobre estafas financieras, negligencia profesional, condenas penales o comportamiento público de funcionarios del gobierno)». Como no podía ser de otro modo, Google apunta a los dos criterios básicos mencionados anteriormente: el interés público de la información, y su carácter actual u obsoleto.

Según se deduce de las explicaciones de Google, la retirada de los enlaces se hará tan sólo de las listas de resultados en búsquedas que incluyan el nombre del afectado, y no en búsquedas para otras palabras ${ }^{76}$. Esta acotación del derecho al olvido a las búsquedas nominativas parece razonable, aunque quizá no es concordante con el tenor literal de la normativa o la sentencia, que teóricamente exigirían la cancelación de los datos en cualquier caso, y no solo para determinadas búsquedas.

En un primer momento, Google señaló que borraría los enlaces tan solo en las extensiones nacionales de su buscador, allí donde residiera el afectado: google. es, google.fr, google.it, etc., pero no en el buscador general google.com, al entender que a éste no le resulta de aplicación la normativa europea o nacional. Sin embargo, en septiembre de 2014 un tribunal francés ha declarado contraria al derecho europeo dicha interpretación restrictiva, y ha condenado a Google por no retirar enlaces del buscador general «.com» ${ }^{77}$. Dicha resolución es plenamen-

75 «Google, perdido en la aplicación del derecho al olvido», Diario El Mundo, 9.9.2014. Disponible en: http://www.elmundo.es/tecnologia/2014/09/09/540f548ee2704e32188b4588. html (última visita: 01.02.2015).

76 Esta interpretación, fruto de una lectura «restrictiva» de la STJUE, ha sido respaldada por la Audiencia Nacional en la temprana SAN 5252/2014, de 29 de diciembre, F. J. $13^{\circ}$.

77 «Primera sanción a Google por no aplicar el derecho al olvido en todo el Mundo», El Confidencial, 30.09.2014. Disponible en: http://www.elconfidencial.com/tecnologia/2014-09-30/ 
te coherente con la normativa europea, no sólo porque resulta indudable que google.com explota igualmente el mercado publicitario europeo y nacional, sino también porque el buscador «.com» produce en los países europeos efectos perjudiciales en el derecho a la protección de datos, con lo que las autoridades nacionales son competentes para actuar, conforme a la doctrina del lugar de producción del daño ${ }^{78}$.

Aunque los documentos emitidos por Google no dicen nada al respecto, resulta imprescindible que Google —y por extensión, el resto de buscadorestramite las solicitudes de retirada con cierta discreción, a fin de evitar el conocido como efecto Streissand, consistente en dar mayor publicidad a una determinada información al pretender acallarla. Este efecto podría producirse igualmente si el buscador, como se ha aventurado que puede hacer, ofreciera los resultados de las búsquedas con la expresa indicación de que algunos contenidos han sido desindexados ${ }^{79}$.

Por otro lado, la vía de aplicación de la sentencia por Google presenta nuevos interrogantes. ¿Tiene el editor derecho a oponerse a la cancelación del enlace en el buscador? ¿Ante quién debe recurrir, ante el propio buscador, o ante un tribunal ordinario? ¿Ser indexado por un buscador forma parte del derecho a la libertad de expresión de un editor? ¿Podría exigirse la indexación de un determinado contenido? ¿Hará Google públicas sus resoluciones del algún modo para dar a conocer sus estándares de interpretación de los derechos? Como se ve, dejar en manos del buscador la decisión sobre qué información se indexa y se ofrece y cuál no, ocasiona serias preguntas de difícil solución. El propio gigante de Internet así lo reconoce así su página web institucional, remitiendo a las agencias de protección de datos locales a aquellas personas que discrepen de las decisiones tomadas por Google. Estas son sus palabras literales: «se trata de decisiones difíciles y, como organización privada, es posible que no nos encontremos en una posición adecuada para decidir sobre tu caso. Si no estás de acuerdo con nuestra decisión, puedes ponerte en contacto con la autoridad de protección de datos local» ${ }^{80}$.

Esta remisión a las autoridades de protección de datos nacionales pone sobre la mesa otra cuestión que no es baladí: la de la constitucionalidad de dejar en manos

primera-sancion-a-google-por-no-aplicar-el-derecho-al-olvido-en-todo-el-mundo_218178/ (última visita: 01.02.2015).

78 Boix Palop, A. (2015). «El equilibro entre los derechos...», op. cit., p. 9.

79 Cotino Hueso, L. (2014). «La STJUE del caso Google vs AGPD de 2014...», op. cit., p. 10 .

80 Privacidad y Condiciones, Preguntas frecuentes. Google. Disponible en: https://www. google.es/intl/es/policies/faq/ (última visita: 01.02.2015). 
de autoridades administrativas — en nuestro caso, de la AEPD— el control de la información en Internet ${ }^{81}$. A través del portillo de la protección de datos, una autoridad administrativa — dependiente en última instancia del Gobierno- se irroga la competencia de ordenar la retirada de contenidos de la Red, en lo que resulta un ejercicio de control de la información dudosamente compatible con el marco constitucional previsto en el artículo $20 \mathrm{CE}$, y desarrollado en las tres últimas décadas por el Tribunal Constitucional ${ }^{82}$. Algunos autores ya han alertado sobre esta dudosa forma de control, hija de una hipertrofiada concepción del derecho a la protección de datos, que justifica la intervención administrativa en unos conflictos cuya trascendencia es, a nuestro entender, fundamentalmente privada.

\subsection{El derecho al olvido: perspectivas de futuro}

El debate en torno al derecho al olvido es un debate incipiente, que sin duda se extenderá todavía algunos lustros más, hasta cristalizar en prácticas sociales, construcciones jurisprudenciales y textos jurídicos proporcionados y justos. Antes de pasar a las conclusiones, nos parece interesante esbozar algunas de las que a nuestro entender serán las líneas futuras de desarrollo del debate, en los ámbitos jurídico, tecnológico y periodístico.

Desde el punto de vista jurídico, hay que consignar que la Comisión Europea está trabajando en un proyecto de Reglamento General de Protección de Datos, del cual presentó un borrador en enero de 2012. El texto, particularmente garantista del derecho al olvido, incluía un artículo 17 con el título «Derecho al olvido y a la supresión». Si bien las enmiendas al borrador aprobadas por el Parlamento Europeo en marzo de 2014 han matizado el tenor del artículo 17, y han eliminado la referencia expresa al «derecho al olvido», el haz de facultades que el nuevo texto reconoce a los afectados por el tratamiento supone un reconocimiento fáctico de su dicho derecho, en la línea de lo que también se conoce como el derecho a la autodeterminación informativa ${ }^{83}$. En cualquier caso, junto

81 Una aproximación interesante a esta cuestión puede consultarse en: BoIx PALOP, A. (2015). «El equilibro entre los derechos...», op. cit., pp. 33 y ss.

82 Cotino Hueso, L. (2010). «La colisión del derecho a la protección de datos personales y las libertades informativas en la red: pautas generales y particulares de solución», en Libertades de expresión e información en Internet y las redes sociales: ejercicio, amenazas y garantías, Valencia, PUV, p. 394.

83 Para una exposición doctrinal del iter recorrido hasta la fecha por el borrador, véase AzURMENDI, A. (2015): «Por un derecho al olvido para los europeos...», op. cit. pp. 279 y ss. Troncoso Reigada entiende que el tenor del artículo 17 apunta al editor del contenido (a quien publica la información) como responsable de garantizar el derecho al olvido, y no tanto al buscador. Estas 
al reconocimiento del derecho al olvido del afectado, la propuesta de Reglamento contiene también una serie de causas de justificación que excluirán la cancelación de los datos, entre las que pueden destacarse las siguientes: cuando la publicación de la información suponga un ejercicio de la libertad de expresión; por motivos de interés público en el ámbito de la salud pública; con fines de investigación histórica, estadística o científica; o cuando la conservación sea necesaria para el cumplimiento de una obligación legal de conservar los datos. Si bien el tenor del artículo propuesto supone un avance respecto a la indeterminación de la normativa actual, quizá sería deseable que la futura normativa se detuviera en la cuestión de la ponderación de derechos en conflicto, explicitando claramente quién y con qué criterios debe llevar a cabo la misma.

Todavía en el campo estrictamente jurídico, será interesante atender a la evolución de la jurisprudencia nacional y comparada, que sin duda irá incorporando matices a la interpretación del derecho al olvido, perfilando sus contornos de modo más preciso.

En el ámbito periodístico, algunos medios de comunicación en Internet han comenzado a ensayar respuestas para garantizar el derecho al olvido de las personas que son mencionadas en sus noticias. Por citar tan solo un ejemplo, en la edición de 2014 del Libro de estilo del Diario El País ya se prevé específicamente la problemática del derecho al olvido. El párrafo 1.57 del Libro de estilo se ocupa de aquellas noticias que el paso del tiempo puede convertir en obsoletas o incompletas, cuya lectura fuera de contexto, y sin las explicaciones de hechos que se produjeron con posterioridad, podría suponer una injusta merma en el honor de la persona afectada. En este sentido, el Libro de estilo señala: «las informaciones archivadas y con acceso desde elpais.com que den cuenta de imputaciones, acusaciones, detenciones, encarcelamientos o condenas que hayan sido revocados por una decisión policial o judicial posterior deberán contener una advertencia al respecto y un enlace con la última información disponible sobre el caso» ${ }^{84}$. Por su parte, el párrafo 1.58 aborda la problemática del derecho

son sus palabras: «Así, frente a quienes han mantenido que el derecho al olvido en Internet debía pivotar sobre el derecho de oposición ejercido sobre los motores de búsqueda como responsables de sus propios tratamientos (...), la propuesta de Reglamento construye el derecho al olvido en Internet sobre las obligaciones del responsable principal — del webmaster- que ha hecho públicos los datos». Troncoso Reigada, A. (2013). «Las redes sociales a la luz de la propuesta de reglamento general de protección de datos personales. Parte dos», IDP: revista de Internet, Derecho y Política, núm. 16, p. 33. Sin embargo, tras la STJUE del caso Costeja, esta posición se ha debilitado, desde el momento en que la STJUE considera también al buscador como responsable principal del tratamiento.

${ }^{84}$ Y prosigue el párrafo: «Si esa última información no se hubiera publicado en su momento, la persona perjudicada podrá reclamar que la notica en cuestión incluya un texto aclaratorio y un 
al olvido respecto de los contenidos veraces, cuando el paso del tiempo recomienda restringir su disponibilidad en la Red. Los criterios establecidos para estos casos son los siguientes: «nunca se producirá el borrado de los archivos digitales de El País, pero se puede considerar la posibilidad de ocultar esa información a los buscadores de Internet». Además, «la información debe haber sido publicada más de quince años atrás respecto del momento en que se reclama su borrado»y «ha de perjudicar a la persona reclamante en su vida familiar o profesional». Por último, el Libro de estilo señala que «no se considerarán las reclamaciones que afecten a hechos que figuren en sentencias firmes de los tribunales y se refieran a actos de violencia» ${ }^{85}$. Como ya se ha mencionado, los medios de comunicación y sus hemerotecas online son unos de los principales implicados en la cuestión del derecho al olvido, por lo que resulta positivo que a través de sus diversas instancias de autorregulación y control vayan estableciendo mecanismos de protección y garantía de los datos personales, equilibrando dicha protección con su ineludible función de información y documentación histórica.

Finalmente, también se ha abierto un debate sobre las herramientas tecnológicas que permitirían el olvido en Internet. Entre las mismas, destacan la herramienta de no indexación, como la etiqueta «.txt», que colocada en un determinado contenido evita su indexación por los buscadores. Este tipo de herramientas será útil para ciertas informaciones particularmente vinculadas con la intimidad, como puede ser el caso de las publicaciones en boletines oficiales o resoluciones judiciales, que a pesar de ser fuentes de acceso público, «contienen una información que eventualmente puede limitar y afectar al libre desarrollo de las personas» ${ }^{86}$. Otra propuesta sobre la mesa es la conocida como tecnología vanish, que consiste en programar los contenidos digitales para su autoeliminación pasado un determinado periodo de tiempo. La idea subyacente aquí es la de asemejar la memoria de Internet a la memoria humana, que olvida las informaciones pasado un determinado periodo de tiempo. Empero, dicha tecnología puede suponer un obstáculo a la investigación histórica, lo que ha suscitado cierto rechazo desde determinados sectores. Quizá una solución intermedia sería la de programar la aparición de la etiqueta que impide la indexación, de modo que no se eliminase el contenido, pero que a partir de un plazo razonable de tiempo, la misma dejara de estar disponible en los buscadores de Internet. Este

enlace con la notificación o sentencia de que se trate». Libro de Estilo de El País, Madrid, Santillana, 2014, pp. 37-38.

85 Ibídem, p. 38.

86 Simón Castellano, P. (2012). El régimen constitucional..., op. cit., p. 202. 
tipo de tecnologías podrían también operar en sentido bidireccional, eliminando la posibilidad de indexación pasados unos años de la publicación, y devolviéndola tras otro plazo de tiempo mayor, con la intención de facilitar la investigación histórica. En tercer lugar, responsables de medios digitales han propuesto el derecho al actualizado o rectificado respecto de ciertas noticias relacionadas con actuaciones policiales o judiciales, como hemos visto que prevé el Libro de estilo de El País. Este derecho supondría la obligación del medio de completar las noticias del pasado que se ofrecen en sus portales con enlaces a noticias relacionadas más recientes, que reflejan cómo termina un procedimiento o actuación judicial. Así, por ejemplo, una noticia acerca de la imputación de un sujeto debería complementarse con un aviso o enlace a una noticia posterior, en la que se diera cumplida cuenta de su absolución por el juez.

\section{CONCLUSIONES (INCONCLUSAS)}

Del análisis seguido hasta aquí cabe extraer pocas conclusiones firmes y numerosos interrogantes por resolver.

1. El derecho al olvido es una concreción del derecho a la protección de datos, reconocido en el artículo $18.4^{\circ}$ de la Constitución y desarrollado, sobre la falsilla de la Directiva 95/46/CE, por la Ley Orgánica 1/1999, de 15 de abril, de Protección de datos de carácter personal. En concreto, es una reformulación de los derechos de cancelación y oposición, reconocidos en el artículo 17 de la LOPD.

2. El debate en torno al derecho al olvido en Internet enfrenta el derecho a la protección de datos de un sujeto (el afectado), con los derechos comunicativos del editor y los internautas, así como con el derecho a la libertad de empresa del buscador. En nuestra opinión, el conflicto se extiende también a los derechos comunicativos del buscador, que ejerce en su actuación los derechos reconocidos en el artículo $20.1^{\circ} \mathrm{CE}$. Esta extensión, sin embargo, no es pacífica en la doctrina, y ha sido expresamente rechazada por el TJUE en la sentencia del caso Costeja. Para resolver este conflicto de derechos, habrá que atender a la veracidad y, sobre todo, al interés público del mensaje que se pretende eliminar. En la medida en que el mismo sea veraz y de interés público, no se podrá exigir su retirada. Si el mismo es impreciso, obsoleto o carente de interés público, podrá exigirse la retirada.

3. Cuando un contenido es ilegal por vulnerar derechos como el honor, la intimidad o la propia imagen, podrá exigirse su retirada de la Red, tanto al editor (conforme a la Ley Orgánica 1/1982, o a otros textos legales) como a los buscadores y otros intermediarios de Internet (conforme a la LSSI). 
4. Conforme a la resolución de la AEPD y a la Sentencia del TJUE en el caso Costeja, cuando un contenido es legal, y tan solo puede vulnerar el derecho a la protección de datos personales, se podrá exigir su retirada al buscador que lo indexa y lo ofrece en sus listas de resultados, mas no necesariamente al editor. $\mathrm{Y}$ ello porque el buscador es considerado un verdadero responsable del tratamiento de los datos, que perpetúa y multiplica el alcance del mensaje perjudicial. Para exigir la retirada, el contenido deberá haber perdido su actualidad o interés público, o resultar impertinente o innecesario. El juicio sobre su mantenimiento o retirada corresponderá en primera instancia al buscador, una vez recibida la solicitud de retirada del interesado. En caso de no ser atendida, el interesado podrá acudir a la AEPD, que resolverá sobre la legitimidad de su pretensión, y, en su caso, ordenará al buscador la retirada.

5. La argumentación seguida por la AEPD y el TJUE no es unánimemente aceptada, y plantea ciertos interrogantes. Los interrogantes más destacados fueron subrayados por el Abogado General en sus Conclusiones para el TJUE en el caso Costeja. Por un lado, resulta dudoso que un buscador sea responsable del tratamiento de datos, en la medida en que es un mero intermediario del contenido, que ni conoce ni valora. Además, en caso de ser responsable, podría acogerse a su derecho a la libertad de empresa y a sus derechos comunicativos, ya que contribuye indudablemente al acceso a la información por parte de los internautas. En este caso, en la medida en que su tratamiento sirve a intereses legítimos, no tiene porqué recabar el consentimiento del afectado. En tercer lugar, encomendarle que como sujeto privado realice la ponderación de los intereses en juego — tratándose de derechos fundamentales — resulta imponerle una potestad arbitral cuestionable, así como una carga de trabajo desproporcionada. Finalmente, también se ha planteado si la resolución del TJUE no estará abriendo la puerta a una censura privada del contenido de la Red, donde el acceso a determinadas informaciones dependerá del juicio de conveniencia realizado por un agente privado.

6. Google, a pesar de haber manifestado su disconformidad con la resolución del TJUE, y como no podía ser de otro modo, está realizando importantes esfuerzos por cumplir con las exigencias de la sentencia. Para ello ha establecido un mecanismo relativamente sencillo de solicitud de retirada. Si bien las líneas básicas del procedimiento se ajustan a lo requerido por el TJUE, algunos de sus criterios de resolución ya han sido cuestionados, como la limitación de la retirada a sus buscadores nacionales, y no al genérico «.com», o la restricción de las solicitudes a las búsquedas nominativas. Resta por ver cómo otros motores de búsqueda y prestadores de servicios en Internet sin la extensión ni los medios 
materiales de Google proceden a cumplir las exigencias de protección de datos que se derivan de la sentencia del TJUE.

7. Valga terminar estas páginas señalando que la regulación de Internet sigue siendo uno de los desafíos más urgentes y apasionantes a los que se enfrenta la ciencia del Derecho a comienzos del siglo XXI. Al tratar de dar respuesta a los interrogantes que la Red de redes plantea, el jurista se enfrenta a una realidad novedosa y cambiante, y se ve abocado a modificar y adaptar una y otra vez las categorías jurídicas con creatividad, audacia y prudencia, para ofrecer soluciones justas a los conflictos que se producen en la sociedad. Y todo ello con el objetivo último de proteger los derechos de las personas, particularmente de los menos poderosos. Este empeño, que en Internet puede asemejarse a veces a la tarea de Sísifo, es la vocación más noble del Derecho.

\section{BIBLIOGRAFÍA}

Azurmendi, A. (2015): «Por un derecho al olvido para los europeos: aportaciones jurisprudenciales de la Sentencia del Tribunal de Justicia Europeo del caso Google Spain y su recepción por la Sentencia de la Audiencia Nacional Española de 29 de diciembre de 2014», Revista de Derecho Político, núm. 92, pp. 273-310.

Borx Palop, A. (2015). «El equilibro entre los derechos del artículo 18 de la Constitución, el derecho al olvido y las libertades informativas tras la Sentencia Google», Revista General de Derecho Administrativo, núm. 38, pp. 1-40.

Catalá i BAs, A. H. (2001). Libertad de expresión e información. La jurisprudencia del TEDH y su recepción por el Tribunal Constitucional, Valencia, Ediciones Revista General de Derecho.

Cernada Badía, R. (2013). «El derecho al olvido judicial en la red», en Libertad de expresión e información en Internet, Madrid, Centro de Estudios Políticos y Constitucionales, pp. 521-541.

Cotino Hueso, L. (2010). «La colisión del derecho a la protección de datos personales y las libertades informativas en la red: pautas generales y particulares de solución», en Libertades de expresión e información en Internet y las redes sociales: ejercicio, amenazas y garantías, Valencia, PUV, pp. 386-401.

- (2014). «La STJUE del caso Google vs AGPD de 2014. Algunos olvidos y otras tendencias negativas respecto de las libertades informativas en Internet», Valencia, Documento online. Disponible en: http://www.uv.es/seminaridret/ sesiones2014/google/ponenciacotino.pdf (última visita: 01.02.2015)

Garriga Domínguez, A. (2012). Fundamentos éticos y jurídicos de las TIC, Cizur Menor, Thomson Reuters-Aranzadi. 
Grimalt Servera, P. (2013): «La falta de conocimiento efectivo del prestador del servicio de intermediación de almacenamiento o alojamiento de datos como causa de exoneración de responsabilidad civil. El conflicto entre el derecho al honor y la libertad de expresión», Cuadernos Civitas de Jurisprudencia Civil, núm. 93, pp. 315-341.

Hernández Ramos, M. (2013). «El derecho al olvido digital en la web 2.0», Cuadernos de la Cátedra de Seguridad Salmantina, núm. 11, pp. 1-43.

Libro de Estilo de El País, Madrid, Santillana, 2014.

Martínez Martínez, R. (2007). «El derecho fundamental a la protección de datos: perspectivas», IDP: revista de Internet, Derecho y Política, núm. 5, pp. 47-61.

Martínez Sospedra, M. (1993). Libertades públicas, v. I, Valencia, Fundación Universitaria San Pablo CEU.

Memoria Anual 2013, Madrid, Agencia Española de Protección de Datos, 2014.

Pérez Velasco M. M. y Conde Castejón, J. (2002). «Regulación versus autorregulación en Internet y los nuevos servicios de comunicación», en Régimen jurídico de Internet, Madrid, La Ley, pp. 119-128.

Rallo Lombarte, A. (2010). «El derecho al olvido y su protección a partir de la protección de datos», Telos: Cuadernos de comunicación e innovación, núm. 85, pp. 104-108.

- (2014). El derecho al olvido en Internet. Google versus España, Madrid, Centro de Estudios Políticos y Constitucionales.

Reding, V. (2010). «Why the EU needs new personal data protection rules?», The European Data protection and Privacy Conference, Bruselas. Disponible en: http://europa.eu/rapid/press-release_SPEECH-10-700_en.htm (última visita: 01.02.2015).

Simón Castellano, P. (2012). El régimen constitucional del derecho al olvido digital, Valencia, Tirant lo Blanch.

De Terwangne, C. (2012). «Privacidad en Internet y derecho a ser olvidado / derecho al olvido», Revista de Internet, Derecho y Política, núm. 13, pp. 53-66.

Touriño, A. (2014). El derecho al olvido y a la intimidad en Internet, Madrid, Catarata.

Troncoso Reigada, A. (2013). «Las redes sociales a la luz de la propuesta de reglamento general de protección de datos personales. Parte dos», IDP: revista de Internet, Derecho y Política, núm. 16, pp. 27-39.

De Verda y Beamonte, J. R. (2014). «Responsabilidad del gestor del motor de búsqueda por los contenidos por la indexación y almacenamiento de datos contenidos en sitios de Internet», Actualidad Jurídica Iberoamericana, núm. 1, pp. 251-258. 
Title:

THE RIGHT TO BE FORGOTTEN ON THE INTERNET: CLOSED DEBATES AND OPEN QUESTIONS AFTER THE CJEU'S DECISION ON THE CASE GOOGLE VS AEPD AND MARIO COSTEJA.

\section{Summary:}

1. Introduction: the right to be forgotten... Mission: Impossible?

2. Previous Issues: actors and interests involved. 3. The right to be forgotten in regard to illegal content. 4 . The right to be forgotten in regard to legal content. 5. Status of the matter: more questions than answers. 6. (Unconcluded) Conclusions. 7. Bibliography.

\section{Resumen:}

Internet y las tecnologías digitales han permitido el desarrollo de poderosas herramientas de comunicación. Junto con ventajas innegables, dicho entorno on line presenta algunos riesgos, como la perpetuación en la Red de ciertas informaciones negativas o perjudiciales referidas a un sujeto. Frente a la memoria total de Internet que permite acceder a cualquier suceso de la vida de alguien sin ningún límite de espacio ni tiempo, ha surgido la pretensión de exigir el derecho al olvido en Internet. La pretensión del olvido en la Red enfrenta diferentes derechos: la libertad de expresión, el derecho a la información, la libertad de empresa, la intimidad, el derecho al honor y el derecho a la protección de datos. Diferentes instancias nacionales y supranacionales han tenido que resolver conflictos de intereses de esta naturaleza, y han adoptado diferentes soluciones. Quizá una de las resoluciones más importantes, llamada a constituir todo un hito histórico en este debate, es la Sentencia del TJUE en el caso Google contra la AEPD y Mario Costeja. Dicha sentencia contienen pronunciamientos muy importantes: se reconoce la aplicabilidad de la normativa europea al motor de búsquedas de Google; se niega a los buscadores la categoría de medios de comunicación o de sujetos ejercientes de los derechos comunicativos; se atribuye a los buscadores una responsabilidad directa sobre el tratamiento de los datos personales que enlazan; y se reconoce el derecho al olvido de los individuos respecto a los enlaces de los buscadores. Empero, la STJUE no es pacífica, como lo evidencia el hecho de que sus pronunciamientos se distancian sensiblemente de las Conclusiones previas redactadas por el Abogado General. El presente artículo pretende analizar el contexto de la Sentencia, su contenido, y las reacciones que ha suscitado, tanto entre la doctrina jurídica más cualificada, como en los principales agentes afectados: el propio buscador de Google, y los medios de comunicación digitales cuyas noticias son indexadas. 


\begin{abstract}
:
Internet and digital technologies have enabled the development of powerful communication tools. Along with undeniable advantages, the online environment presents some risks, such as the perpetuation of certain negative or harmful information relating to persons. In this humus, where the total memory of the Internet allows access to any event in the life of someone without limit in space or time, has emerged the demand to the right to be forgotten online. The claim of oblivion on the Net contrasts different rights: freedom of expression, right to information, freedom of enterprise, privacy, the right to honor and the right to data protection. Different national and supranational bodies have had to resolve juridical conflicts of this nature, and have adopted different solutions. Perhaps one of the most important decisions in this matter, called to be an historic milestone in this debate, it is the judgment of the CJEU in the case Google versus AEPD and Mario Costeja. This decision contains very important statements: the applicability of European legislation to Google's search engine; the exclusion of Internet search engines from the category of Media and from the protection of the communicative rights; the attribution of a direct responsibility for the treatment of personal data to the Internet search engines; and the recognition to the right to be forgotten of individuals with regard to the links included in the results list of the Internet search engines. However, the reception of the CJEU's decision has not been peaceful. In fact, the Court decision was significantly distant from the previous Conclusions of the Advocate General. This paper analyzes the context of the decision, its content, and the reactions it provoked both among the most qualified legal doctrine, as in the main parties concerned: Google search engine itself, and digital Media whose news are indexed.
\end{abstract}

\title{
Palabras clave:
}

derecho al olvido, Internet, derechos comunicativos, buscadores de Internet.

\section{Keywords:}

right to be forgotten, Internet, freedom of speech, Internet search engines. 